\title{
Evaluating the Experimental High-Resolution Rapid Refresh-Alaska Modeling System Using USArray Pressure Observations
}

\author{
Taylor A. McCorkle, John D. Horel, And Alexander A. Jacques \\ Department of Atmospheric Sciences, University of Utah, Salt Lake City, Utah
}

TreVOR ALCOTT

NOAA/Earth System Research Laboratory, Boulder, Colorado

(Manuscript received 23 October 2017, in final form 26 April 2018)

\begin{abstract}
The High-Resolution Rapid Refresh-Alaska (HRRR-AK) modeling system provides 3-km horizontal resolution and $0-36-h$ forecast guidance for weather conditions over Alaska. This study evaluated the experimental version of the HRRR-AK system available from December 2016 to June 2017, prior to its operational deployment by the National Centers for Environmental Prediction in July 2018. Surface pressure observations from 158 National Weather Service (NWS) stations assimilated during the model's production cycle and pressure observations from 101 USArray Transportable Array (TA) stations that were not assimilated were used to evaluate 265 complete $0-36$-h forecasts of the altimeter setting (surface pressure reduced to sea level). The TA network is the largest recent expansion of Alaskan weather observations and provides an independent evaluation of the model's performance during this period. Throughout the study period, systematic differences in altimeter setting between the HRRR-AK 0-h forecasts were larger relative to the unassimilated TA observations than relative to the assimilated NWS observations. Upon removal of these initial biases from each of the subsequent 1-36-h altimeter setting forecasts, the model's 36-h forecast root-mean-square errors at the NWS and TA locations were comparable. The model's treatment of rapid warming and downslope winds that developed in the lee of the Alaska Range during 12-15 February is examined. The HRRR-AK 0-h forecasts were used to diagnose the synoptic and mesoscale conditions during this period. The model forecasts underestimated the abrupt increases in the temperature and intensity of the downslope winds with smaller errors as the downslope wind events evolved.
\end{abstract}

\section{Introduction}

Alaska's vast landmass spans more than $20^{\circ}$ of latitude, consists of 13 unique climate zones ranging from maritime to polar, and contains rugged topography at elevations from near sea level to Denali $(6190 \mathrm{~m})$, the highest point in North America (Searby 1968; Shulski and Wendler 2007; Shulski et al. 2010; Bieniek et al. 2012, 2016). During Alaska's warm season (May-September), longer days and higher sun angles allow for enhanced surface heating that is conducive to unstable conditions, convection, and wildfires, especially in Alaska's interior (Grice and Comisky 1976; Reap 1991; Partain et al. 2016). Most climate regions in Alaska receive the bulk of their annual precipitation during the warm season, with the exception of some

\footnotetext{
Corresponding author: Taylor McCorkle, taylor.mccorkle@utah. edu
}

maritime and high-elevation locations (Shulski and Wendler 2007). The long interior Alaska cold season (October-April) is susceptible to year-to-year variations (such as the anomalous warmth during the 2015/16 winter) with increasing concerns regarding potential impacts of anthropogenic warming (Shulski et al. 2010; Bieniek et al. 2014; Cassano et al. 2016; Walsh et al. 2017).

Weather in Alaska is influenced by interactions between planetary circulation features on time scales of weeks and months and the synoptic-scale weather systems embedded within them (Bieniek et al. 2012; Cullather et al. 2016). A number of planetary-scale signatures, or teleconnections, are known to affect Alaska's weather, for example, the Arctic Oscillation (AO; Thompson and Wallace 1998) and the Pacific-North American pattern (PNA; Papineau 2001; Bieniek et al. 2011). These low-frequency perturbations to the planetary-scale circulation modulate the development, progression, and demise of synoptic-scale features such as 
Aleutian lows (Wilson and Overland 1986; Rodionov et al. 2005).

We examine synoptic and mesoscale conditions in Alaska from December 2016 through June 2017. Using the National Centers for Environmental Prediction (NCEP)-National Center for Atmospheric Research (NCAR) reanalysis described by Kalnay et al. (1996), large positive 500-hPa geopotential height and sea level pressure departures from normal were evident during the study period's winter (December-March 2017) with weaker anomalies in the spring (April-June 2017). The regional circulation during December was characterized by the negative phase of the PNA and the positive phase of the AO, leading to ridging aloft over Alaska and a weakened Aleutian synoptic storm track. Despite the weakened Aleutian storm track, above average precipitation was observed in some parts of the state during the 2017 winter (Alaska Climate Research Center 2017). Given Alaska's low climatological average precipitation amounts during winter (monthly totals of $\sim 1$ in. or less for the Alaskan interior from November to March), the passage of a few troughs can produce above average monthly precipitation totals (Shulski and Wendler 2007). As the winter progressed, the magnitude of the AO teleconnection pattern weakened and the phase of the PNA became slightly positive, leading to a persistently weak wintertime storm track across the Aleutians and the Gulf of Alaska. The dominant storm track remained south of Alaska during spring with dry conditions during April followed by above normal rainfall during May.

Although the state of Alaska encompasses 1.718 million $\mathrm{km}^{2}$, there are only 158 automated weather stations supported by the National Weather Service (NWS) and the Federal Aviation Administration, generally located at airports around the state. MesoWest (Horel et al. 2002) facilitates the monitoring of surface environmental conditions in Alaska at over 750 additional stations maintained by federal and state agencies, commercial firms, and the public. The data obtained, archived, and disseminated by MesoWest, with funding from the NWS National Mesonet Program, are made publicly available via generalized and specialized web products (e.g., mesowest.utah.edu and akff.mesowest.org) and Application Programming Interface (API) services (synopticlabs.org).

The largest expansion of in situ weather observing capabilities in Alaska in decades began in 2014 as part of EarthScope's USArray Transportable Array (TA), a research seismic monitoring network currently deployed in Alaska and adjacent Canadian provinces (Jacques et al. 2015, 2016a,b, 2017; Tytell et al. 2016). The TA network by December 2016 consisted of 101 stations with microbarographs that continuously measure atmospheric pressure at a frequency of $1 \mathrm{~Hz}$. To expand the operational and research applications of the network, EarthScope began deploying Vaisala WXT520 all-inone weather sensors at TA sites in 2016. However, only 44 of those stations were deployed by December 2016.

By themselves, surface weather observations in Alaska are insufficient to characterize the evolution of weather conditions across the state. There are several operational numerical weather prediction systems available that assimilate observations from diverse sources and provide hourly guidance in Alaska. Currently, output from numerical weather prediction systems available in Alaska range from the global scale to the mesoscale: the NCEP Global Forecast System (GFS; Environmental Modeling Center 2003; National Weather Service 2014), version 4 of the Rapid Refresh data assimilation/modeling system (RAPv4; Benjamin et al. 2016), and the Alaskan North American Mesoscale Forecast System (NAM) nest (Janjić 2003).

The objective of our study was to evaluate Alaskan weather forecasts from the experimental High-Resolution Rapid Refresh-Alaska (HRRR-AK) model being developed by the Earth System Research Laboratory that will become operational in July 2018. This modeling system uses 51 hybrid sigma-pressure levels in the vertical and 3-km horizontal grid spacing, nested within the larger domain of the RAPv4. The HRRR-AK cycles every $3 \mathrm{~h}$ (0000, 0300, 0600 UTC, etc.) with hourly forecast output fields available out to $36 \mathrm{~h}$. The HRRR-AK is initialized with output from a 1-h "preforecast," which is generated using downscaled initial conditions from the RAPv4 forecast initialized $1 \mathrm{~h}$ prior to the current HRRR-AK model run. Each of the 36 hourly forecasts is constrained by downscaled boundary conditions from the RAPv4 forecast cycle initialized $3 \mathrm{~h}$ prior.

There has been considerable interest from model developers, researchers, and operational forecasters to assess the performance of the HRRR-AK prior to its operational deployment. Complementing HRRR-AK verification efforts under way by other researchers, this study evaluates the model's ability to analyze and forecast the spatial and temporal evolution of surface pressure relative to surface observations. HRRR-AK forecasts of surface pressure during a 7-month period (1 December 2016-30 June 2017) are evaluated herein at lead times from 0 to $36 \mathrm{~h}$. The GFS forecasts of surface pressure will also be validated relative to the same surface observations used in the HRRR-AK evaluation. The GFS 0-36-h surface pressure forecasts will serve as a baseline for comparison to the HRRR-AK forecasts as they are the only operational forecast grids accessible retrospectively for this period. 
The HRRR-AK forecasts are validated relative to observations in two categories: 1) NWS/FAA observations that were assimilated by the RAPv4 and HRRRAK models and 2) TA pressure observations that were not assimilated. Sensor technologies allow for accurate in situ measurement of surface pressure. When ignoring the variations that arise from the underlying topography, surface pressure tends to be more representative of conditions over larger distances than other nearsurface variables such as temperature, moisture, or wind (Benjamin et al. 1999; Ancell 2012; Madaus et al. 2014). Assuming a standard atmospheric temperature profile, reducing the surface pressure to sea level yields the altimeter setting, which can be used to examine horizontal pressure gradients arising from weather features. As will be explained in more detail later, computing sea level pressure is not possible from many of the USArray stations since air temperature sensors were not deployed at those sites. In addition, altimeter setting is already widely used and understood in Alaska by the aviation community given the inability to access much of the state because of the limited road network around the state.

Incorrect station elevation and imperfect assumptions about the air temperature profile extrapolated downward to sea level are generally the largest sources of error for applications of altimeter setting (Mohr 2004). Nonetheless, surface pressure and altimeter setting have been used extensively to diagnose the accuracy of numerical weather prediction model forecasts, including the position and intensity of individual cyclones and anticyclones (Colucci and Bosart 1979; Charles and Colle 2009; Mesquita et al. 2010; Wheatley and Stensrud 2010) and aggregate statistics over a portion of or an entire model domain (Charles and Colle 2009; McMurdie and Casola 2009).

In addition to the assessment of HRRR-AK cumulative pressure errors over the 7-month period using NWS/ FAA and TA observations, a case study of a strong downslope wind event in the lee of the Alaska Range during 12-15 February 2017 will be presented to investigate a period of low HRRR-AK forecast skill. Strong winds in excess of $20 \mathrm{~m} \mathrm{~s}^{-1}$ during two successive days were accompanied by as much as a $35^{\circ} \mathrm{C}$ temperature increase over $36 \mathrm{~h}$ within the Fort Greely mesonet available via MesoWest. The rapid warming and onset of the downslope windstorm allows for an evaluation of the model's performance when weather conditions are rapidly changing. Downslope windstorms have been studied extensively at various locales across Alaska (Murray 1956; Colman and Dierking 1992; Overland and Bond 1993; Hopkins 1994; Nance and Colman 2000) and in the continental United States, including northern Utah (Lawson and Horel 2015a,b). This study will examine the ability of HRRR-AK model analyses and forecasts to capture the spatial and temporal variability of 2-m temperature, potential temperature, $10-\mathrm{m}$ wind speed, and 10-m wind gusts during the 12-15 February 2017 event, but will not attempt to improve the welldocumented understanding of downslope windstorms in Alaska or elsewhere.

Characteristics of the TA network, other observational and validation assets, and the HRRR-AK modeling system will be described in section 2, followed by 7-month HRRR-AK verification statistics and a case study analysis of the 12-15 February 2017 downslope wind event in section 3 .

\section{Data and methods}

\section{a. Meteorological observations}

As shown in Fig. 1a, there are currently 158 stations in Alaska operated by the NWS or under contract by the FAA that generate hourly or subhourly reports of conventional meteorological variables (pressure, temperature, moisture, wind, etc.) in the form of aviation routine weather reports (METARs). The METAR data are disseminated through various channels and are assimilated into the RAPv4 and HRRR-AK models for forecast initialization. Generally, METAR reports are obtained in locales with small variations in terrain variability (surface roughness), as defined by the standard deviation of surface elevation within the sample of the nine closest HRRR-AK model grid points (Fig. 1a).

EarthScope's USArray TA is a research network of seismic monitoring stations deployed by the Incorporated Research Institutions for Seismology (IRIS). Beginning in 2004, this array of stations migrated eastward across the contiguous United States and is now being deployed as shown in Fig. 1b across the state of Alaska in a quasi grid with an average spacing of $85 \mathrm{~km}$ (Yang and Ritzwoller 2008; Pavlis et al. 2012; Jacques et al. 2015; Tytell et al. 2016). Because of the impact that low-frequency, largeamplitude atmospheric acoustic signals have on measuring seismic activity, each TA station is equipped with a Setra-278 barometric pressure sensor with observations available at $1 \mathrm{~Hz}$ (Tytell et al. 2016). We will highlight in section 4 that EarthScope is currently deploying Vaisala WXT520 all-in-one weather sensors at many TA sites in order to expand the operational and research applications of the network. However, since few of those Vaisala sensors were deployed prior to 2017, data obtained from them will not be used in this study.

Since 1 March 2012, the pressure data from all TA stations have been obtained from IRIS, averaged over 5-min intervals, and made available publicly via MesoWest (Jacques et al. 2015). In addition, a web interface was designed specifically for the TA data, which displays 


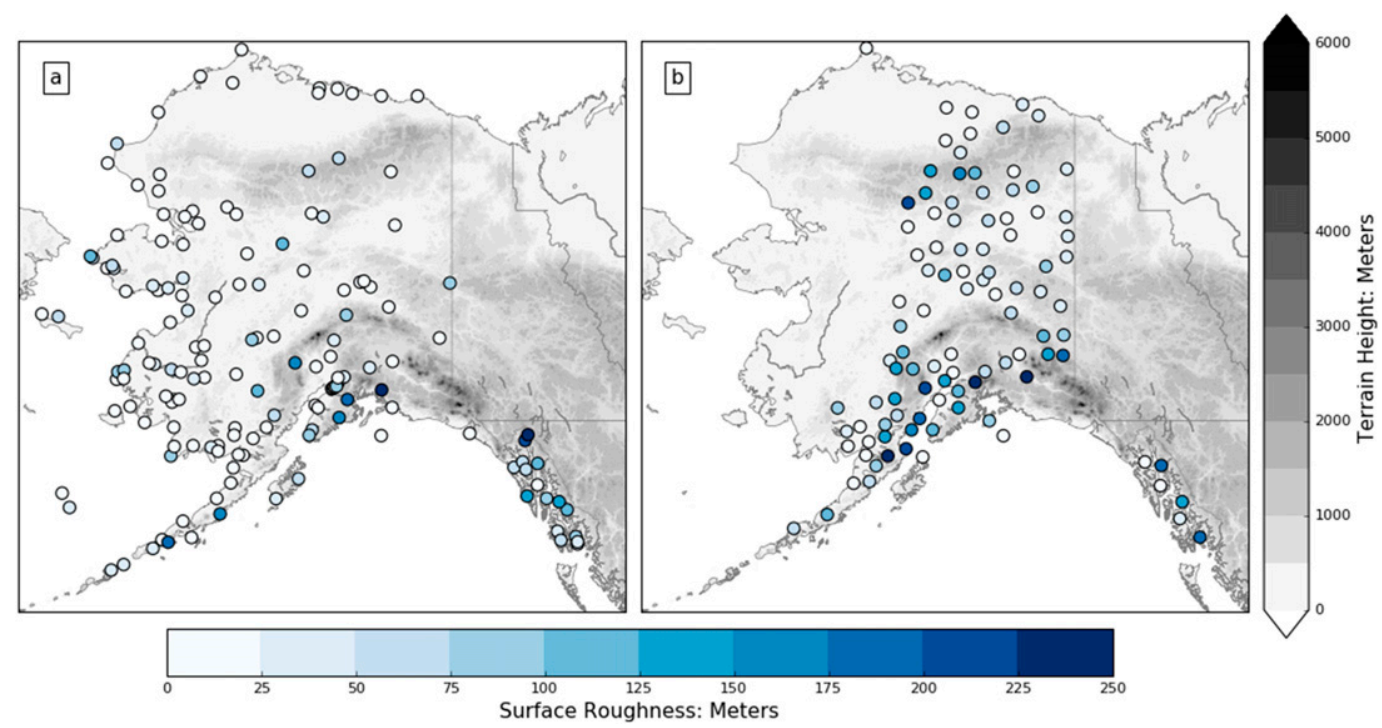

FIG. 1. Surface roughness ( $\mathrm{m}$; circles shaded according to the scale at the bottom) defined as the standard deviation of HRRR-AK terrain values computed from the sample of the nine closest grid points to (a) NWS stations and (b) TA stations. In both panels, HRRR-AK terrain height $(\mathrm{m})$ is shaded in gray according to the scale on the right.

current observations and has tools for filtering pressure perturbations and constructing time series (http://meso1. chpc.utah.edu/usarray/). Given the recognized quality of the TA dataset, the atmospheric pressure data archive described by Jacques et al. (2016a) and including the more recent data from Alaska can also be accessed via the National Center for Atmospheric Research Research Data Archive (https://rda.ucar.edu/).

The TA stations in Alaska are generally located in remote areas and are often subject to harsh conditions (e.g., on exposed ridgelines, etc.). As shown in Fig. 1, the surface roughness defined by the standard deviation of the HRRR-AK terrain in the vicinity of the TA sites is much higher on average $(76.3 \mathrm{~m})$ than that found around the NWS/FAA stations $(36.9 \mathrm{~m})$. A mix of subjective and objective quality control checks has been applied to the TA $1-\mathrm{Hz}$ data that is similar to that used by Jacques et al. (2015). Subjectively, the data are checked using reports from the Array Network Facility, and if the data appear corrupt, they are flagged. Objectively, data gaps longer than $5 \mathrm{~min}$ or pressure changes with a magnitude greater than or equal to $2 \mathrm{hPa} \mathrm{s}^{-1}$ are flagged. Flagged data are not deleted from the archive but deemed suspicious and are not used in this study. Despite the remote locations of many TA sites and the lack of solar power during much of the winter for the northernmost sites, only $11 \%$ of the total hourly observations were missing or failed quality control checks. For comparison, the NWS stations (generally electrically powered and more accessible for routine maintenance and repair) had $12.7 \%$ missing or unusable data.
Surface observations at 5-min intervals of 10-m wind, 2-m temperature, and pressure from 15 sites in the Fort Greely mesonet are used to examine conditions in the upper Tanana valley during two downslope windstorm events during 12-15 February 2017 . These observations were obtained from the MesoWest archive.

\section{b. $H R R R-A K$}

The HRRR-AK has been under development over the past several years. A major upgrade and domain expansion in late November 2016 improved the stability of the model's configuration, and enhanced automated retrieval of forecast grids from ESRL after March 2017 provided the opportunity to extend the winter-only period of record examined by McCorkle (2017). The experimental 3-km HRRR-AK receives initial and boundary conditions from the 13-km RAPv4 model and uses the same data assimilation and physical parameterization schemes (Benjamin et al. 2016). The RAPv4, implemented operationally in August 2016, employs the NOAA Gridpoint Statistical Interpolation (GSI) system for hourly data assimilation processing (Wu et al. 2002; Whitaker et al. 2008; Kleist et al. 2009). Referring to the flowchart in Fig. 2, the HRRR-AK uses the initial conditions from the previous RAPv4 forecast cycle $\left(t_{0}-1 \mathrm{~h}\right)$ at each initialization time $t_{0}$ and boundary conditions from the RAPv4 forecast cycle $3 \mathrm{~h}$ prior to the initialization time $\left(t_{0}-3 \mathrm{~h}\right)$. HRRR-AK forecasts begin with a 1-h preforecast from the downscaled RAPv4 initial and boundary conditions to improve the representation of small-scale (e.g., terraindriven) features prior to data assimilation. Conventional 


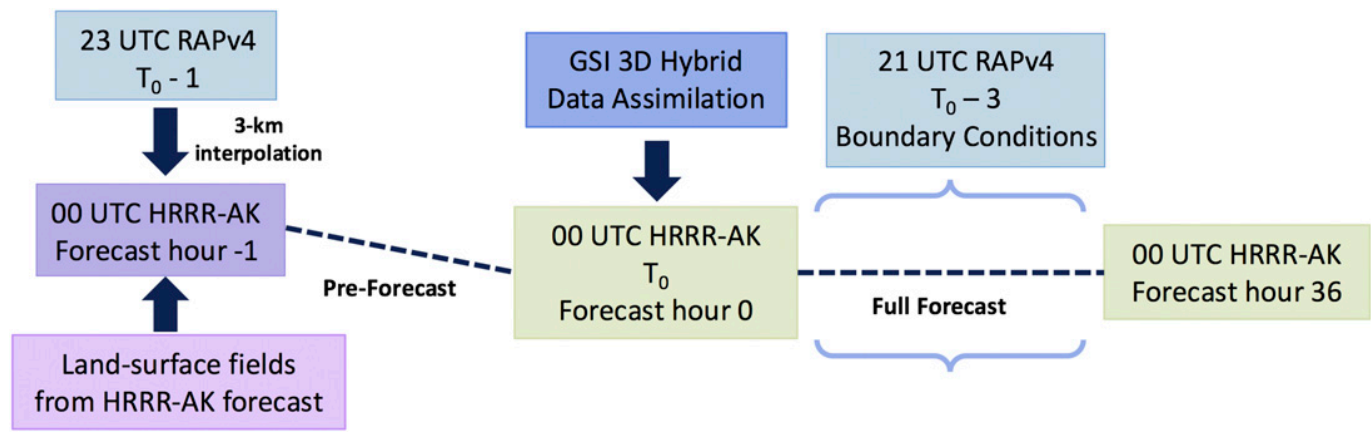

FIG. 2. Data assimilation process for the HRRR-AK modeling system.

observations and satellite data are then assimilated by GSI using a 3D hybrid ensemble Kalman filter method at forecast hour 0 , and a full forecast follows out to $36 \mathrm{~h}(\mathrm{Hu}$ et al. 2017). RAPv4 and HRRR-AK use the Weather Research and Forecasting (WRF) Model's version 3.8 dynamical core (Skamarock et al. 2008). Given the WRF's nonhydrostatic capabilities, the HRRR-AK is run in convection-permitting mode without a cumulus parameterization (Benjamin et al. 2016).

The HRRR-AK surface and pressure level gridded binary version 2 (GRIB-2) files were downloaded locally via FTP and stored in an Amazon Simple Storage Service archive (Blaylock et al. 2017). Given the experimental status of the HRRR-AK during the study period, complete model runs are not available every $3 \mathrm{~h}$ of every day. During this 7-month study period, 1249 (73.6\%) of the 0 -h forecasts were available. The focus here was on examining those model runs for which the gridded data files have been available and archived for each hourly forecast (0-36h). For example, $67 \%$ (58\%) of the model runs initialized at 0000 (1200) UTC are complete. For each available 0 - and 36-h forecast surface file, the data from the grid points nearest to the NWS and TA stations were extracted for comparison with the actual observations.

To further assess the ability of the HRRR-AK to accurately forecast altimeter setting, the GFS was evaluated in a similar manner and will serve as a basis for a model intercomparison over the same domain and time frame. The GFS is a medium-range global numerical weather prediction system that initializes forecasts four times a day (0000, 0600, 1200, and 1800 UTC), out to 16 days in the future. For its data assimilation processes, the GFS modeling system employs a GSI three-dimensional variational ensemble Kalman filter-variational hybrid system (Wang et al. 2013). The GFS surface GRIB-2 files were downloaded locally at $0.25^{\circ}$ horizontal resolution from the NCAR Research Data Archive (NCEP 2015). While most of the fields are interpolated operationally to $13-\mathrm{km}$ horizontal resolution, they are not accessible from the National Centers for Environmental Information, NCAR, or other data repositories to which we had access. To ensure a consistent comparison of the two modeling systems, only GFS forecast cycles initialized at the same time as the complete 0000 and 1200 UTC HRRR-AK runs were used to calculate forecast skill metrics.

\section{c. Analysis methods}

To focus on meteorologically relevant pressure variations and for consistency among the data sources, surface pressure from the TA stations, HRRR-AK grids, and GFS grids are converted to altimeter setting. Altimeter setting observations at NWS stations are included in METAR reports. Conversion of surface pressure to altimeter setting requires only the surface pressure and station elevation assuming a temperature distribution below ground defined by the standard atmosphere temperature profile (Bluestein 1992; Pauley 1998).

The HRRR-AK and GFS forecast surface pressure grids were converted to altimeter setting using surface pressure and elevation grids and the same standard atmosphere temperature profile used for the TA stations. Despite its 3-km grid spacing, the HRRR-AK's terrain field is still too coarse to accurately resolve Alaska's terrain for most locales (Fig. 1). Even if the HRRR-AK gridded surface pressure value exactly matches that observed by a TA station, discrepancies between the model grid elevation interpolated to the station location can lead to consistent differences between the model and the station altimeter setting of $\sim 1 \mathrm{hPa}(8 \mathrm{~m})^{-1}$ difference in elevation. To focus on the model's ability to predict altimeter setting at the station locations, the difference at each station location between the 0-h forecast and the observed altimeter setting (referred to hereafter as the initial bias) is then subtracted from the subsequent model altimeter settings for each of the 36 hourly surface pressure forecasts. Thus, the "error" of the model's 0-h altimeter setting after removal of the initial bias is zero, and any discrepancies at later forecast times reflect model performance, not model misrepresentation of the terrain. 

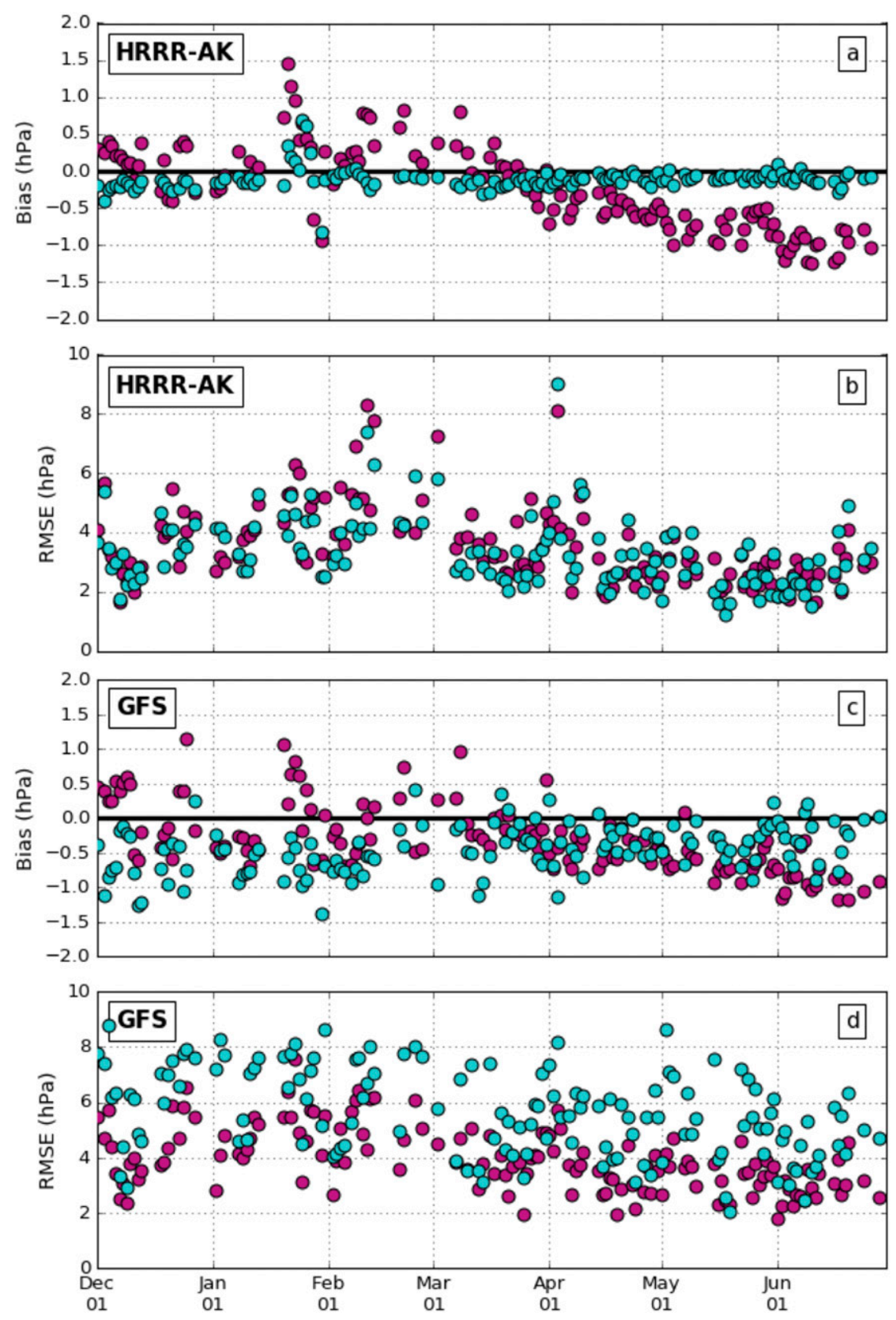

FIG. 3. (a) Average HRRR-AK 0 -h forecast bias ( $\mathrm{hPa}$ ) of the altimeter setting at each 0000 UTC valid time relative to the observations from the TA (magenta) and NWS (blue) networks. (b) Average RMSE (hPa) of the HRRR-AK altimeter setting 36-h forecasts initialized at 0000 UTC relative to observations from the TA (magenta) and NWS (blue) networks with the 0-h bias in (a) removed. (c) As in (a), but using the GFS altimeter setting forecasts, and (d) as in (b) but for GFS altimeter setting forecasts.

To examine sectors within the HRRR-AK's large domain $(\sim 3600 \mathrm{~km} \times 2800 \mathrm{~km})$ that reflect areas of high interest to residents of Alaska, stations are grouped to examine the model's performance in those locales. The regions highlighted in this study are the Fairbanks-Tanana valley region, which represents a continental climate, and the Anchorage-south-central Alaska region, which is a maritime-continental transition climate. Statewide and subregional aggregate statistical analyses of altimeter setting in terms of seasonal bias and root-mean-square error (RMSE) will be presented. 

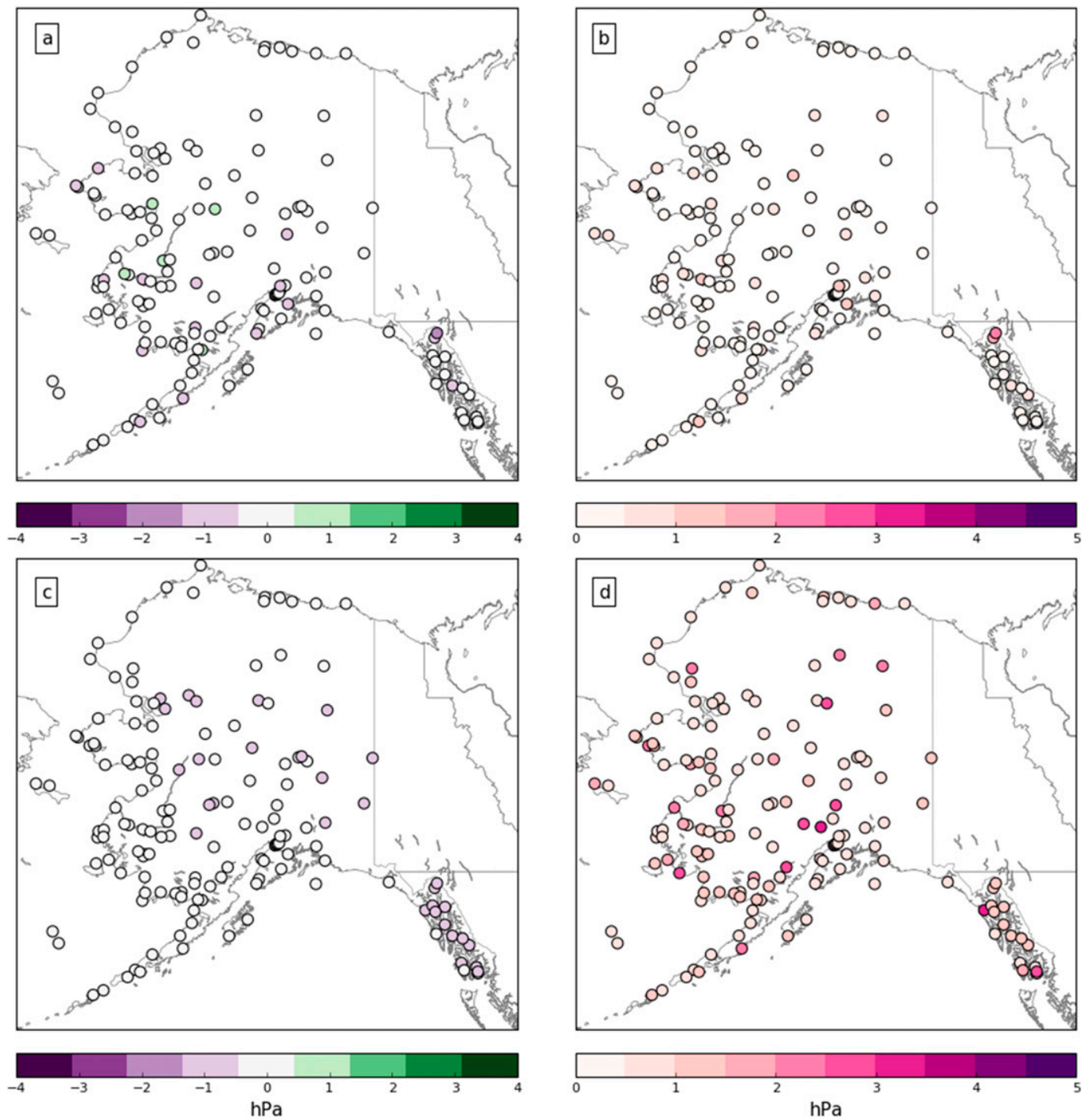

FIG. 4. (a) December 2016-June 2017 average initial bias (hPa; shaded according to the scale at the bottom) derived from all available 0000 and 1200 UTC HRRR-AK altimeter setting 0-h forecasts relative to corresponding observations from NWS stations. (b) As in (a), but for average initial RMSE. (c) As in (a), but for 36-h forecasts with the 0-h bias removed. (d) As in (b), but for 36-h forecasts with the 0-h bias removed.

\section{Results}

\section{a. Cumulative statistics}

Figures $3 \mathrm{a}$ and $3 \mathrm{c}$ show the initial biases of the HRRR$\mathrm{AK}$ and GFS altimeter setting 0 -h forecasts for which complete 0000 UTC HRRR-AK model runs are available, after averaging over all available NWS and TA stations in Alaska. The experimental HRRR-AK modeling system remained stable during our 7-month evaluation period with the exception of initial testing and eventual implementation of the WRF hybrid sigmapressure vertical coordinate in the RAPv4 and the HRRR-AK. The transition from the sigma to the hybrid vertical coordinate helped reduce spurious vertical and horizontal accelerations over steep model terrain that affected upper-level wind forecasts (Klemp 2011). The model developers for the RAPv4 and HRRR-AK tested this implementation extensively and found that atmospheric fields below $500 \mathrm{hPa}$ were unaffected by the coordinate change. The hybrid coordinate was initially implemented on 17 December 2016, turned off on 18 January 2017 for further testing, and then reinstated on 15 March 2017.

Throughout the study period, the average initial biases from the HRRR-AK relative to the NWS observations generally fall between 0.0 and $-0.25 \mathrm{hPa}$, indicating that 

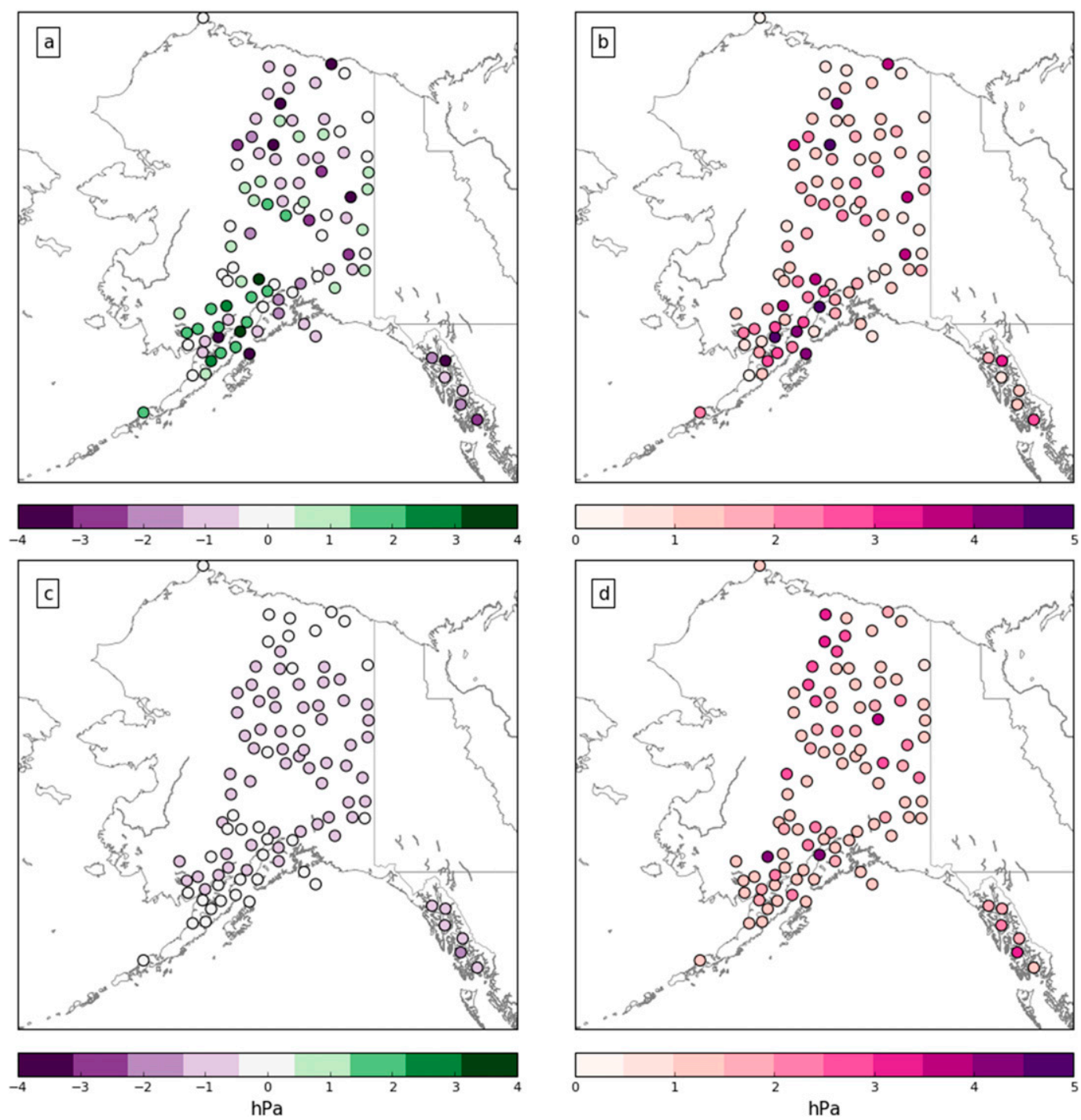

FIG. 5. As in Fig .4, but relative to corresponding observations from TA stations.

the model's assimilation cycle used the pressure observations from the NWS stations (Fig. 3a). These biases do not exhibit much variability over the 7 months with the exception of the 18-22 January 2017 period. Higher biases during that period resulted from the complexity of the code transition back to the sigma vertical coordinate that led to problems with model initialization and assimilation of surface observations. In contrast, the average initial biases of the GFS relative to the NWS are larger and vary more from day to day, with values generally falling between 0.0 and $-1.25 \mathrm{hPa}$ (Fig. 3c). The HRRR-AK biases relative to the TA observations tend to be positive during the first 4 months of the study period (with higher errors during the 18-22 January period) and then become on average roughly $-1 \mathrm{hPa}$ after mid-March. A similar trend is displayed in the GFS initial biases relative to the TA network (Fig. 3c). This suggests that the general negative bias trend relative to the TA may be a function of seasonal differences. Additionally, the magnitude of the HRRR-AK biases at the TA locations throughout the study period is not surprising given potential discrepancies between the elevations of the TA stations relative to the model's terrain nearby, as is evident from Fig. 1. The average initial biases from the HRRR-AK and GFS 1200 UTC 0-h forecasts exhibit tendencies similar to those evident in Figs. 3a and 3c (not shown).

Figures $3 \mathrm{~b}$ and $3 \mathrm{~d}$ quantify the average RMSEs for each HRRR-AK and GFS 0000 UTC 36-h forecast, respectively. These 36-h RMSE values were calculated after removing the initial bias and averaging over all available NWS and TA stations. The HRRR-AK RMSE values generally fluctuate in the range of $2-6 \mathrm{hPa}$ with no 


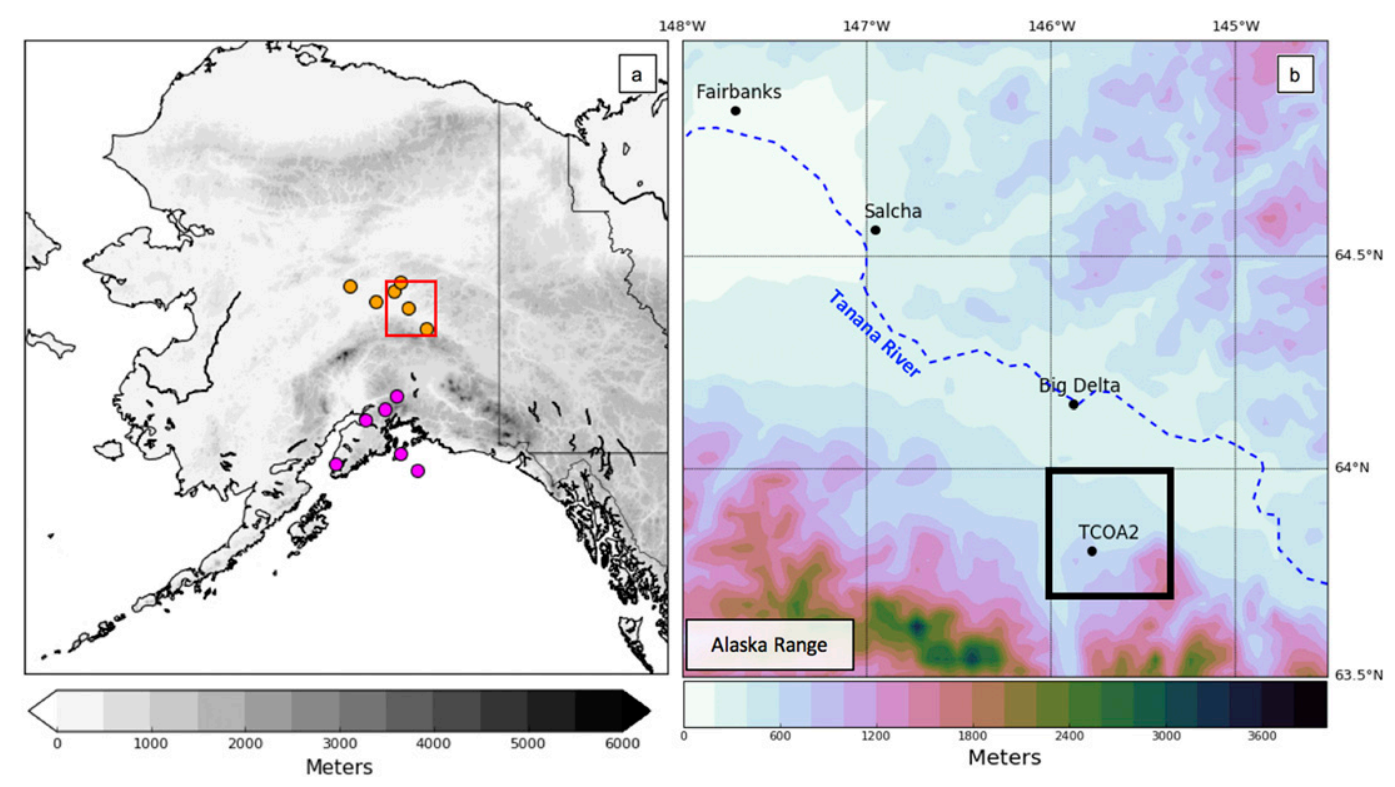

FIG. 6. (a) Locations of the Fairbanks-Tanana valley stations (orange) and Anchorage-south-central Alaska stations (purple) used for regional analysis. HRRR-AK surface elevation $(\mathrm{m})$ is shaded in gray according to the scale at the bottom. (b) The region of interest for the 12-14 Feb 2017 case study shown by the red box in (a). Weather conditions during the case study are examined using observations from the Fort Greely mesonet, outlined by the black box in (b), with emphasis on station TCOA2.

consistent differences between the RMSEs computed relative to the TA and NWS stations (Fig. 3b). The GFS RMSE values are similarly random, appearing with larger day-to-day variability, typically ranging from 3 to $9 \mathrm{hPa}$ (Fig. 3d). This finding shows that, despite removal of the initial biases, the GFS is less skillful than the HRRR-AK at forecasting altimeter setting at longer lead times throughout the 7-month period, relative to both the NWS and TA networks. In both models, there is no strong correspondence between model runs, with higher initial biases leading to larger 36-h forecast RMSEs values. Reduced pressure errors after midMarch, especially with regard to the HRRR-AK in Fig. 3b, may have resulted from seasonal changes in the amplitude of the pressure fluctuations. Some of the highest values of 36-h forecast RMSEs from the HRRRAK relative to NWS and TA stations occurred for the forecasts initialized on 12 and 14 February, respectively. In contrast, the GFS did not exhibit higher 36 -h forecast RMSE values during 12-14 February. This period will be examined in greater detail in the next subsection.

Spatial variations in the bias and RMSE of the HRRR-AK 0- and 36-h forecasts computed from all complete 0000 and 1200 UTC model runs are shown in Figs. 4 and 5 for NWS and TA stations, respectively. As expected from the time series of the 0 -h biases computed over all of these stations (Figs. 3a,b), the initial biases at most NWS stations tend to be within $\pm 1 \mathrm{hPa}$ (Fig. 4a) while those at the TA sites are within $\pm 4 \mathrm{hPa}$ (Fig. 5a). Hence, the 0-h forecast RMSE values are much smaller at the NWS stations (Fig. 4b) compared to those at the TA sites (Fig. 5b) since the HRRR-AK 0-h forecasts are not constrained by those observations. For the GFS, the 0-h biases and RMSE values with respect to both networks were much larger in magnitude, with 0 -h biases ranging between \pm 2 and $4 \mathrm{hPa}$ for most NWS and TA stations (not shown). After removal of the 0 -h biases, average biases from 0 to $-1 \mathrm{hPa}$ from the HRRR-AK 36-h forecasts are evident at both the NWS and TA sites (Figs. 4c and $5 \mathrm{c}$ ). Similarly, the average biases of the GFS 36-h forecasts ranged between -1 and $1 \mathrm{hPa}$ relative to both the NWS and TA stations (not shown). The 36-h RMSE values computed for the HRRR-AK relative to the NWS and TA sites have comparable magnitudes of $1-3 \mathrm{hPa}$ as well (Figs. 4d and 5d). A similar pattern was evident for the 36-h RMSE values from the GFS relative to the TA stations, with locally higher RMSE values relative to the NWS stations (not shown). Hence, the TA observations provide a credible independent evaluation of the model's accuracy after the initial biases derived from the differences between the 0 - $\mathrm{h}$ forecasts and observations are removed.

Selected TA stations in the Fairbanks-Tanana valley (interior Alaska) and Anchorage-south-central Alaska regions (Fig. 6a) are used to illustrate the altimeter setting errors as a function of forecast lead time averaged over 

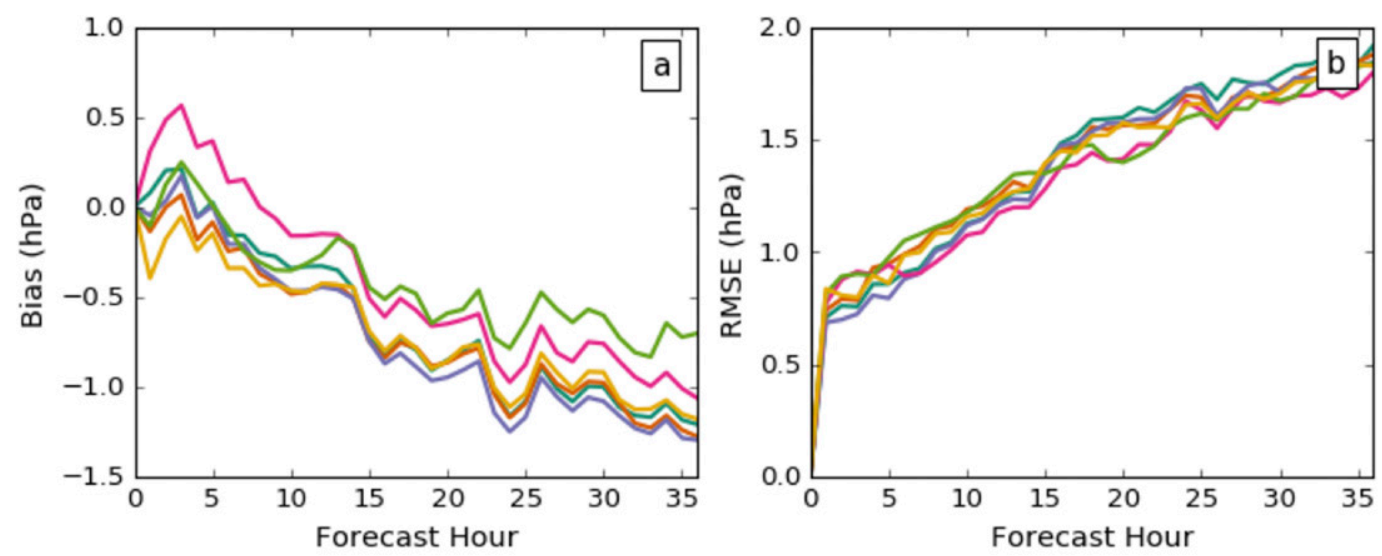

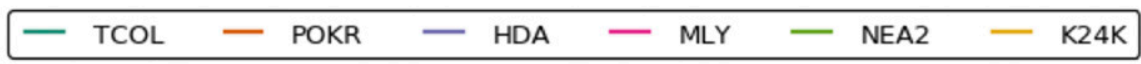
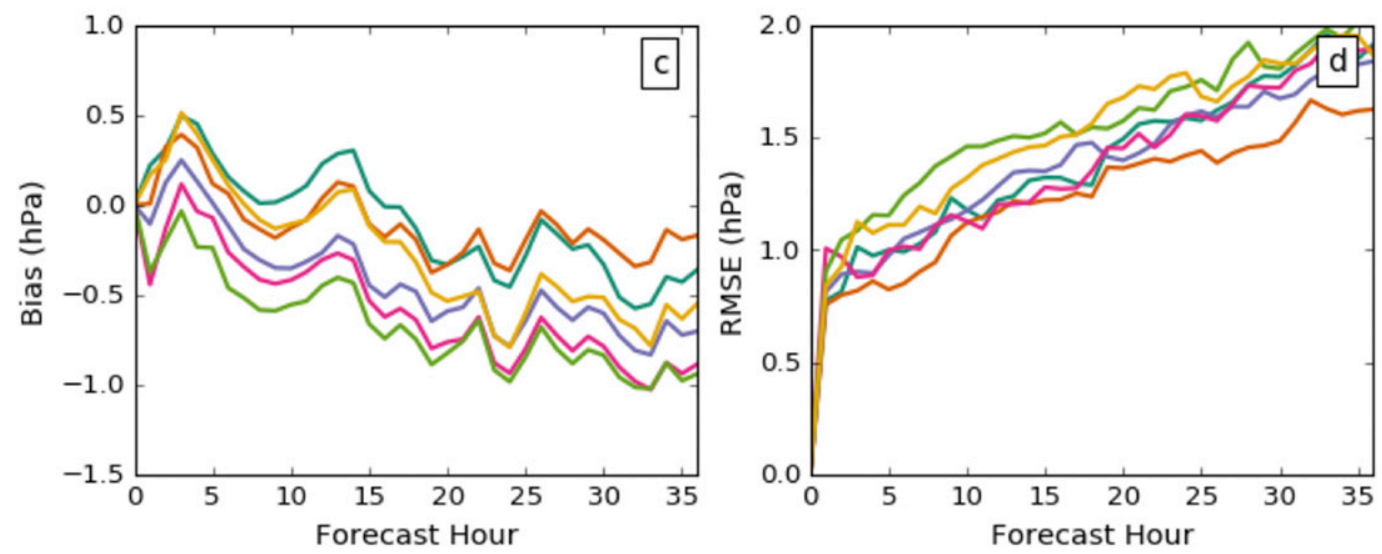

$$
\text { - } 2 \text { Q23K }-\mathrm{HOM}-\mathrm{RCO1}-\mathrm{KNKX}-\mathrm{M} 23 \mathrm{~K}-\mathrm{P} 23 \mathrm{~K}
$$

FIG. 7. (a) December 2016-June 2017 average bias computed for 0-36-h forecasts derived from all available complete 0000 and 1200 UTC HRRR-AK model runs, with the 0-h bias removed relative to corresponding observations from the six TA stations in the Fairbanks-Tanana valley region shown in Fig. 6. (b) As in (a), but for average RMSE. (c) As in (a), but for 36 hourly forecasts with the 0-h bias removed relative to corresponding observations from the six TA stations in the Anchorage-south-central Alaska region shown in Fig. 6. (d) As in (c), but for average RMSE.

all complete 0000 and 1200 UTC model runs from the HRRR-AK (Fig. 7). With 0-h biases removed, the average negative pressure error increases with increasing forecast lead time at a greater magnitude for the interior Alaska sites (Fig. 7a) compared to the south-central Alaska sites (Fig. 7c). The GFS did not exhibit this same negative trend at the interior and south-central sites, but rather the average lead-time biases oscillated between \pm 0.25 and $\pm 0.5 \mathrm{hPa}$, respectively, through forecast hour 36 (not shown). Comparing Figs. 7a and 7b, the small difference in the magnitudes of the RMSE and bias for the interior stations suggest these pressure errors are dominated by the bias. However, in Figs. 7c and 7d, the differences between the magnitudes of RMSE and bias are larger at longer lead times for the south-central Alaska sites, which likely reflect the higher variability in pressure of the systems traversing that region. While the average lead-time bias for the GFS did not exhibit this negative trend over the $0-36-\mathrm{h}$ forecast period, the model's lead-time RMSE values quickly became asymptotic at $2.5 \mathrm{hPa}$ after forecast hour 10 for both regions (not shown).

The results presented in this section highlight the aggregate behavior of the HRRR-AK surface pressure field as a function of period within the winter and spring seasons, locale within Alaska, and forecast lead time. Independent of whether the observations may have been assimilated (NWS) or not (TA), the aggregate 

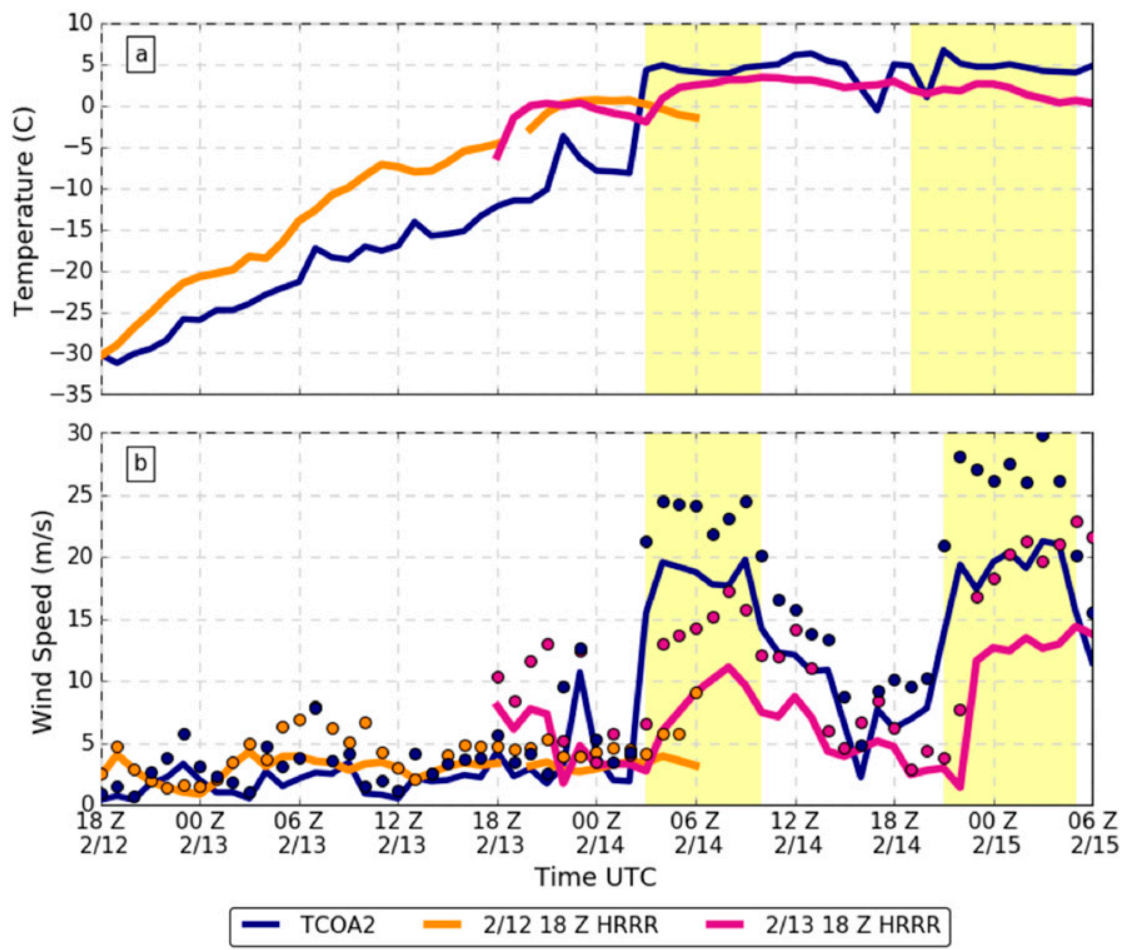

FIG. 8. TCOA2 hourly observations (blue) of (a) 2-m temperature $\left({ }^{\circ} \mathrm{C}\right.$ ) and (b) wind speed ( $\mathrm{m} \mathrm{s}^{-1}$; solid lines) and gusts ( $\mathrm{m} \mathrm{s}^{-1}$; dots) with HRRR-AK forecasts initialized at 1800 UTC 12 Feb (orange) and 13 Feb (magenta). The yellow-shaded areas denote the two periods of downslope winds.

statistics tend to be similar once the initial large differences in altimeter setting between the HRRR-AK analyses and TA observations are removed. These results were then compared to similar methods for the GFS pressure fields with respect to the TA and NWS stations across space and time. Over the 7-month study period, the HRRR-AK generally exhibited smaller-magnitude forecast errors as a function of space, time, and forecast lead time at both the TA and NWS stations when compared to the errors from the GFS forecasts at the same station locations.

\section{b. 12-15 February 2017 case study}

Prior to 12 February 2017, high surface pressures dominated the central and eastern Alaskan interior, contributing to the occurrence of clear skies and enhanced nocturnal radiational cooling over snow-covered surfaces, a strongly stably stratified boundary layer, and frigid surface air temperatures as low as $-45^{\circ} \mathrm{C}$ in the Tanana valley (Fig. 6b). Local conditions changed rapidly during the $12-15$ February period, leading to two distinct downslope wind events in the Fort Greely area of the Tanana valley immediately to the north of the Alaska Range (black box inset in Fig. 6b). For decades, operational forecasters have recognized the difficulties in forecasting strong downslope wind events downstream of the Alaska Range, especially in the Tanana valley (Murray 1956).

\section{1) LOCAL CONDITIONS NEAR FORT GREELY}

To provide context for the evaluation for the HRRR$\mathrm{AK}$ analyses and forecasts across the model domain as well as locally, meteorological observations from the Fort Greely mesonet are used to characterize the key components of the event. The changes in temperature and wind in the Fort Greely area are highlighted in Figs. 8-10. Temperatures steadily increased from $-30^{\circ}$ to $-10^{\circ} \mathrm{C}$ from 1800 UTC 12 February until 0200 UTC 14 February (Fig. 8a) while the wind speeds remained below $5 \mathrm{~m} \mathrm{~s}^{-1}$ during that period (Fig. 8b). An abrupt temperature increase of $13^{\circ} \mathrm{C}$ in $10 \mathrm{~min}$ (0250-0300 UTC 14 February; Fig. 8a) was accompanied by a jump to wind speeds in excess of $15 \mathrm{~m} \mathrm{~s}^{-1}$ that were then sustained from 0300 to 1000 UTC 14 February (Fig. 8b). This first downslope wind event (0300-1000 UTC 14 February) was characterized by increasing temperatures and strong southerly winds confined close to the lee of the upstream ridgeline of the Alaska Range, as shown by the MesoWest data for the Fort Greely mesonet in Fig. 9a. A second period of sustained southerly winds in excess of $15 \mathrm{~m} \mathrm{~s}^{-1}$ occurred from 

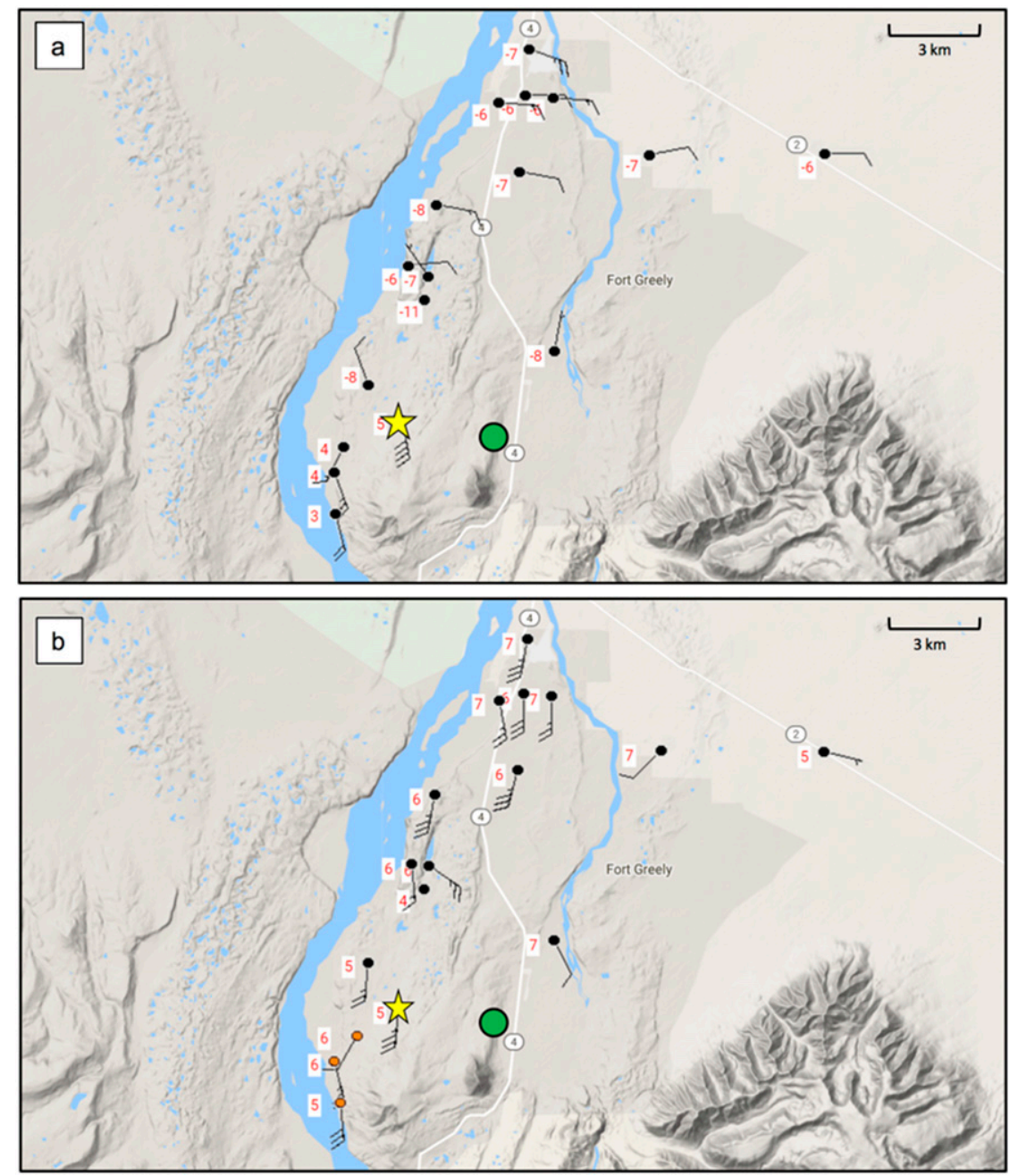

FIG. 9. MesoWest data from the Fort Greely mesonet (area outlined by black box in Fig. 6b). Observations of $10-\mathrm{m}$ wind speed and direction $\left(\mathrm{m} \mathrm{s}^{-1}\right)$ and $2-\mathrm{m}$ temperature $\left({ }^{\circ} \mathrm{C}\right.$; red numbers) are shown for (a) 0300 UTC 14 Feb and (b) 0000 UTC 15 Feb. Case study station TCOA2 (yellow star) and a nearby TA station, K24KX (green circle), are shown. Half, full, and flag wind barbs represent $2.5,5$, and $25 \mathrm{~m} \mathrm{~s}^{-1}$, respectively.

2100 UTC 14 February through 0500 UTC 15 February (Fig. 8a). These strong winds not only resulted in additional warming at the TCOA2 station (Fig. 8b), but also extended to mesonet stations farther north into the Tanana valley (Fig. 9b). The pressure changes observed throughout the event at TCOA2 and a nearby TA site (K24KX; within $3 \mathrm{~km}$ of TCOA2) are nearly identical and include a 12-hPa drop in $12 \mathrm{~h}$ from 0600 to 1800 UTC 13 February followed by another 9-hPa drop in the $10 \mathrm{~h}$ prior to the lowest pressure of the period at 2000 UTC 14 February as the valley's stable layer aloft eroded (not shown).

The HRRR-AK model runs spanning these downslope wind events are examined, focusing on the forecasts initialized at 1800 UTC 12 February and
1800 UTC 13 February. Specifically, the HRRR-AK forecasts of 2-m temperature, 2-m potential temperature, and $10-\mathrm{m}$ wind are evaluated relative to the Fort Greely mesonet observations. Surface winds forecasted at TCOA2 remained light throughout the 1800 UTC 12 February model run, while the forecast cycle initialized at 1800 UTC 13 February underestimated the intensity of both downslope wind periods by $\sim 10 \mathrm{~m} \mathrm{~s}^{-1}$ (Fig. 8b). During the forecast cycle initialized at 1800 UTC 12 February, the model's warming of the valley was too rapid, resulting in temperature errors of $+10^{\circ} \mathrm{C}$ at TCOA2 by 1200 UTC 13 February (Fig. 8a). The abrupt warming associated with the onset of the first downslope wind event is missed by both model runs, with temperatures too high at 1800 UTC 13 February and then roughly comparable to 

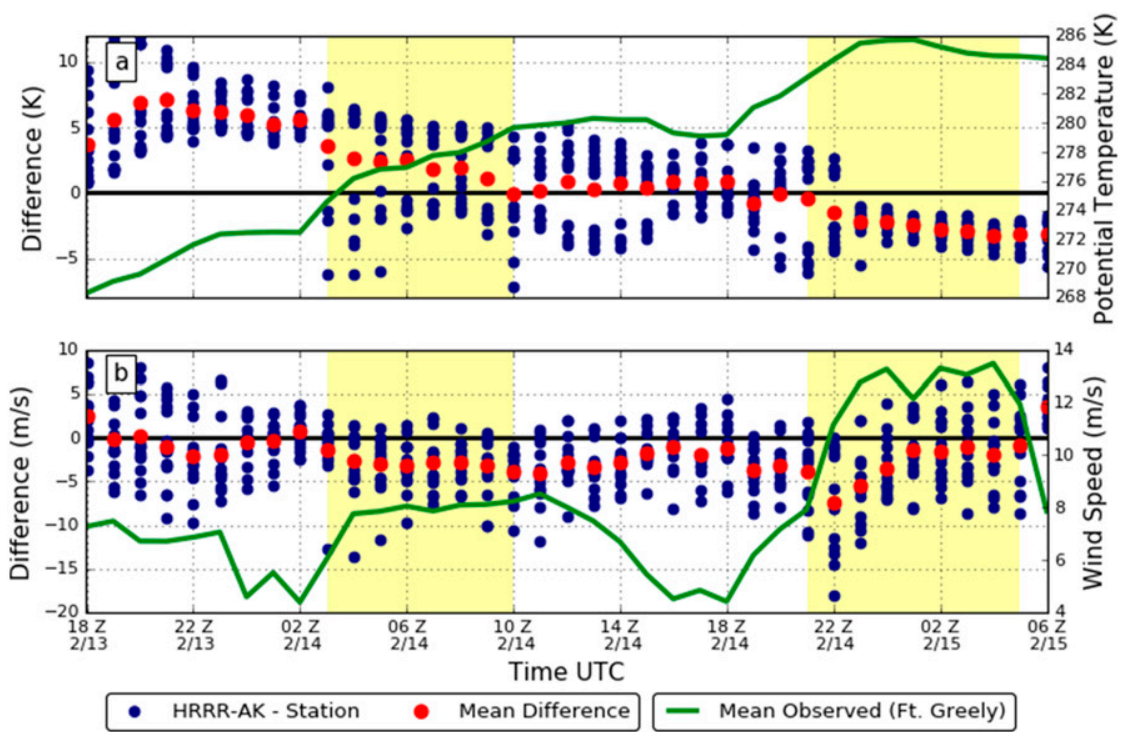

FIG. 10. Observations at hourly intervals averaged over the 14 Fort Greely mesonet sites (solid green lines relative to right axes): (a) potential temperature (K) and (b) wind speed $\left(\mathrm{m} \mathrm{s}^{-1}\right)$. Differences (blue dots relative to left axes) between the 1800 UTC 13 Feb HRRR-AK hourly forecasts and observations at each station. Average differences for the 14 sites (red dots relative to left axes). The yellow-shaded areas denote the two periods of downslope winds.

observations once the downslope wind event was under way. For both model runs, the forecasted altimeter setting values were much too low (errors in excess of $10 \mathrm{hPa}$ ) after $24 \mathrm{~h}$ at both TCOA2 and K24KX (not shown). As mentioned in the previous section, we speculate that such excessive warming and reduced pressure in the model are likely coupled and a common occurrence in interior Alaska during winter.

The variability in model forecast accuracy of potential temperature and wind speed across the 15 Fort Greely mesonet sites during these two downslope wind events is examined in Fig. 10 for the HRRR-AK model run initialized at 1800 UTC 13 February. The potential temperature allows temperature changes on the model grid to be contrasted with those from the mesonet stations that vary in elevation by as much as $200 \mathrm{~m}$. The green lines in Fig. 10 represent the average of the observations over all 14 sites, highlighting the increase in potential temperature throughout the period and the two downslope wind events. Prior to the onset of the first downslope windstorm, the average potential temperature differences between the model forecasts and observations were $\sim 5 \mathrm{~K}$ (red dots), which was also evident by the higher temperatures forecasted at TCOA2 (Fig. 8a). By the end of the forecast period, the model potential temperatures were on average lower than those observed. The mean near-zero wind speed errors (red dots) for this model run result from the large spread in wind speed errors among the 14 stations (blue dots). There are two clusters of potential temperature errors in Fig. 10a during the first downslope wind event resulting from the northernmost extent of the downslope winds: potential temperatures were too low within the downslope winds and too high farther north within the remaining cold air in the Tanana valley. In addition, forecasted wind speeds tended to be too low at sites experiencing the downslope winds and too high farther north (Fig. 10b). During the second downslope wind event (2100 UTC 14 February-0500 UTC 15 February), the downslope winds mixed out the capping stable layer, allowing widespread warming to reach the valley floor. During this period, the model's forecasts of potential temperature at all sites tended to be lower than observed with lower spread in the model errors (Fig. 10a). The forecasted onset time of the downslope winds was delayed by $1-2 \mathrm{~h}$, leading to underestimates of wind speed at the outset but as the event continued, the forecasted winds at some locations were too large (Fig. 10b).

\section{2) SyNOPTIC AND MESOSCALE SETTING}

A deepening, midtropospheric trough characterized the synoptic weather pattern over western Alaska on 12 February 2017. By 14 February, this trough plunged southward into the Gulf of Alaska, while an upper-level ridge situated over the Northwest Territories of Canada remained relatively stationary. Figures $11 \mathrm{a}$ and $11 \mathrm{c}$ show midtropospheric conditions at 1200 UTC 13 February and 1200 UTC 14 February, respectively. The short-wave trough, evident from the low temperatures and strong 

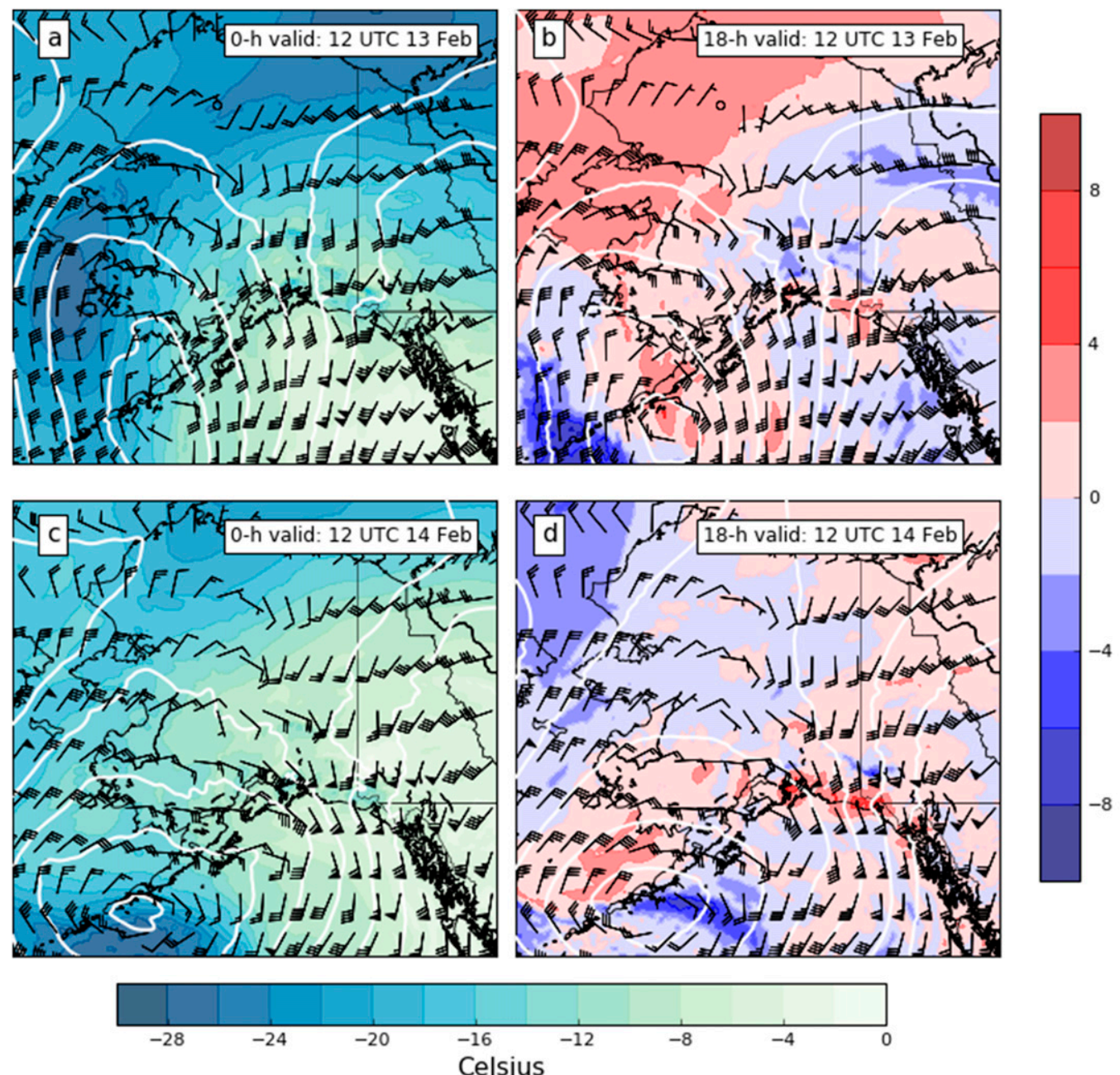

FIG. 11. HRRR-AK 700-hPa geopotential height (white contours at 60-m intervals) and wind speed and direction (a) valid at 1200 UTC $13 \mathrm{Feb}(0$-h forecast) with $700-\mathrm{hPa}$ temperature shaded according to the scale below and (b) valid at 1200 UTC $13 \mathrm{Feb}$ (18-h forecast) with differences between 18 -h forecast 700 -hPa temperature relative to the verifying 0 -h forecast in (a) shaded according to scale on the right. (c) As in (a), but valid at 1200 UTC 14 Feb. (d) As in (b), but valid at 1200 UTC 14 Feb. Half, full, and flag wind barbs represent 5, 10, and $25 \mathrm{~m} \mathrm{~s}^{-1}$, respectively.

winds embedded along the western edge of the largerscale cutoff low on 13 February (Fig. 11a), progressed southward and deepened the cutoff low located south of the Aleutian Islands by 1200 UTC on 14 February (Fig. 11c). Strong warm-air advection in the midtroposphere and the strongest $700-\mathrm{hPa}$ winds on the eastern periphery of the cutoff low shifted northward across the Alaska Range during this 24-h period. Later, the embedded short wave continued to spin within the cutoff low, leading to a shift in the orientation of the trough axis from southwest-northeast at 1200 UTC 14 February to south-north by 1200 UTC 15 February (not shown).

Figures $11 \mathrm{a}$ and $11 \mathrm{c}$ show the 0 -h forecasts valid at 1200 UTC 13 February prior to the onset of the downslope winds and 1200 UTC 14 February after the first downslope wind event for 700-hPa wind, geopotential height, and temperature. Corresponding 18-h forecasts valid at those times are shown in Figs. 11b and 11d with the temperature field replaced by the differences between those 18 -h forecasts of $700-\mathrm{hPa}$ temperature relative to the verifying 0 -h forecasts. Overall, the 18 -h forecasts were quite good at capturing the general sense of the prevailing synoptic situation at these times. However, the 1800 UTC 12 February model run overdeepened the cutoff low (Fig. 11b), and the 1800 UTC 13 February run shifted the cutoff low too far west (Fig. 11d). While the 700-hPa temperature gradients in the 18 -h forecasts are reasonably close to those in the 0 -h forecasts (not shown), the 18-h forecasts of southerly 700-hPa winds impinging into southern Alaska and 


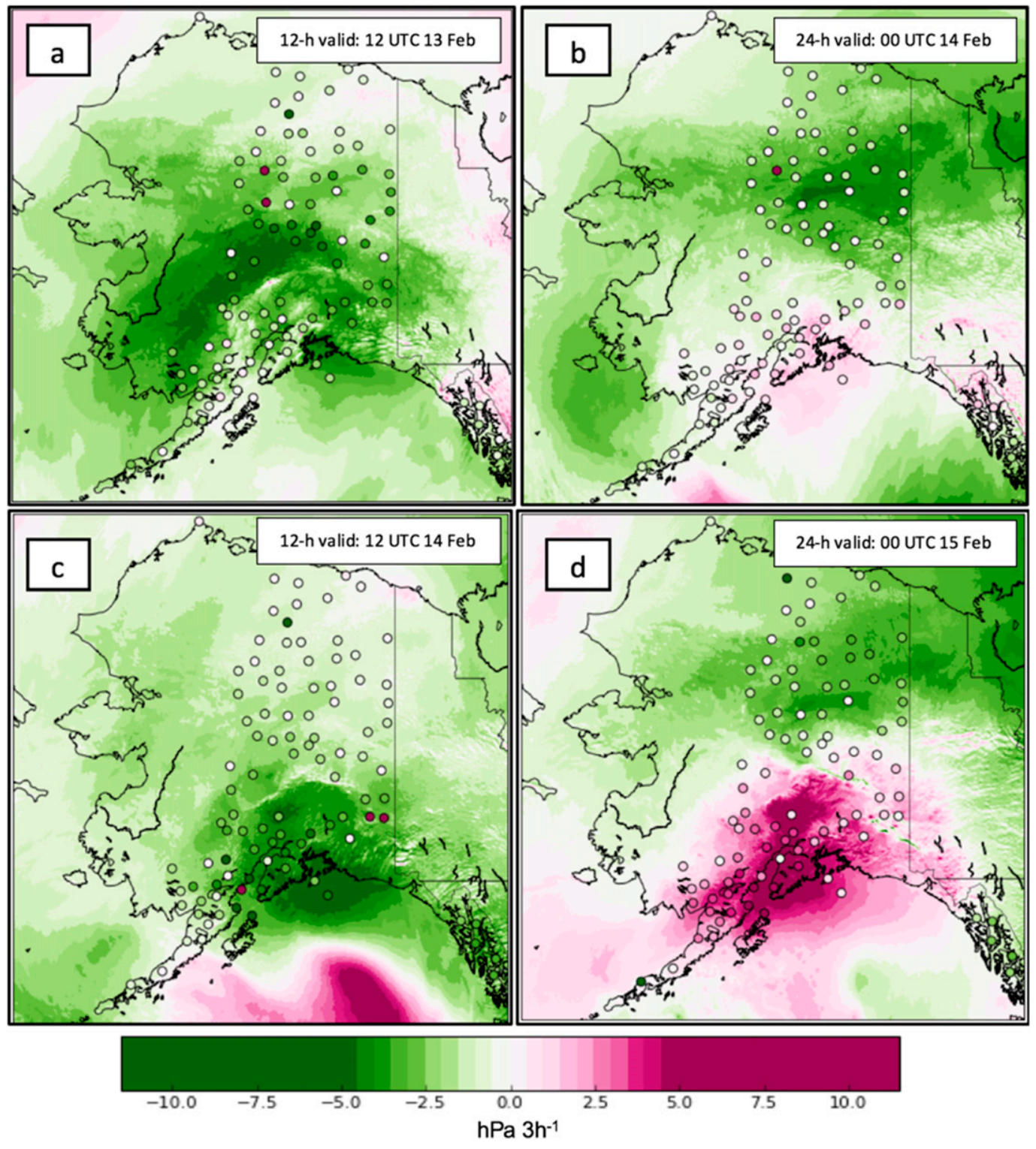

FIG. 12. The 3-h forecast tendency of the HRRR-AK altimeter setting $\left[\mathrm{hPa}(3 \mathrm{~h})^{-1}\right.$; shaded according to the scale at the bottom] and 3-h tendency of the altimeter setting [hPa $(3 \mathrm{~h})^{-1}$; shaded circles] observed by the TA stations valid at (a) 1200 UTC 13 Feb (12-h forecast), (b) 0000 UTC 14 Feb (24-h forecast), (c) 1200 UTC 14 Feb (12-h forecast), and (d) 0000 UTC 15 Feb (24-h forecast).

across the Alaska Range are approximately $5-10 \mathrm{~m} \mathrm{~s}^{-1}$ too strong, leading to excessive midtropospheric warming by 1200 UTC 14 February (Fig. 11d).

The evolution of altimeter setting during this event is illustrated in terms of the 3-h change in altimeter setting observed at TA stations and forecasted by the HRRR-AK model at lead times of $12 \mathrm{~h}$ (Figs. 12a and 12c) and $24 \mathrm{~h}$ (Figs. 12b and 12d). From 0900 to 1200 UTC 13 February before the downslope wind events, pressures were observed to fall at many TA stations, but the 12-h HRRRAK forecasts appeared to lower the pressures more than observed, particularly to the west of the Alaska Range (Fig. 12a). At this time, forecast pressures were also falling too rapidly at TA sites in the Fairbanks-Tanana valley region (Fig. 6b). For the 3-h period ending at 0000 UTC 14 February (Fig. 12b), the north-south-oriented pressure gradient across the Alaska Range is enhanced as a result of increasing pressure in the Anchorage-Kenai Peninsula area and nearly steady pressures to the north of the range. The 24 -h forecast 3 -h pressure tendencies valid at 0000 UTC 14 February are too strongly negative in the north in this region between 0900 and 1200 UTC 

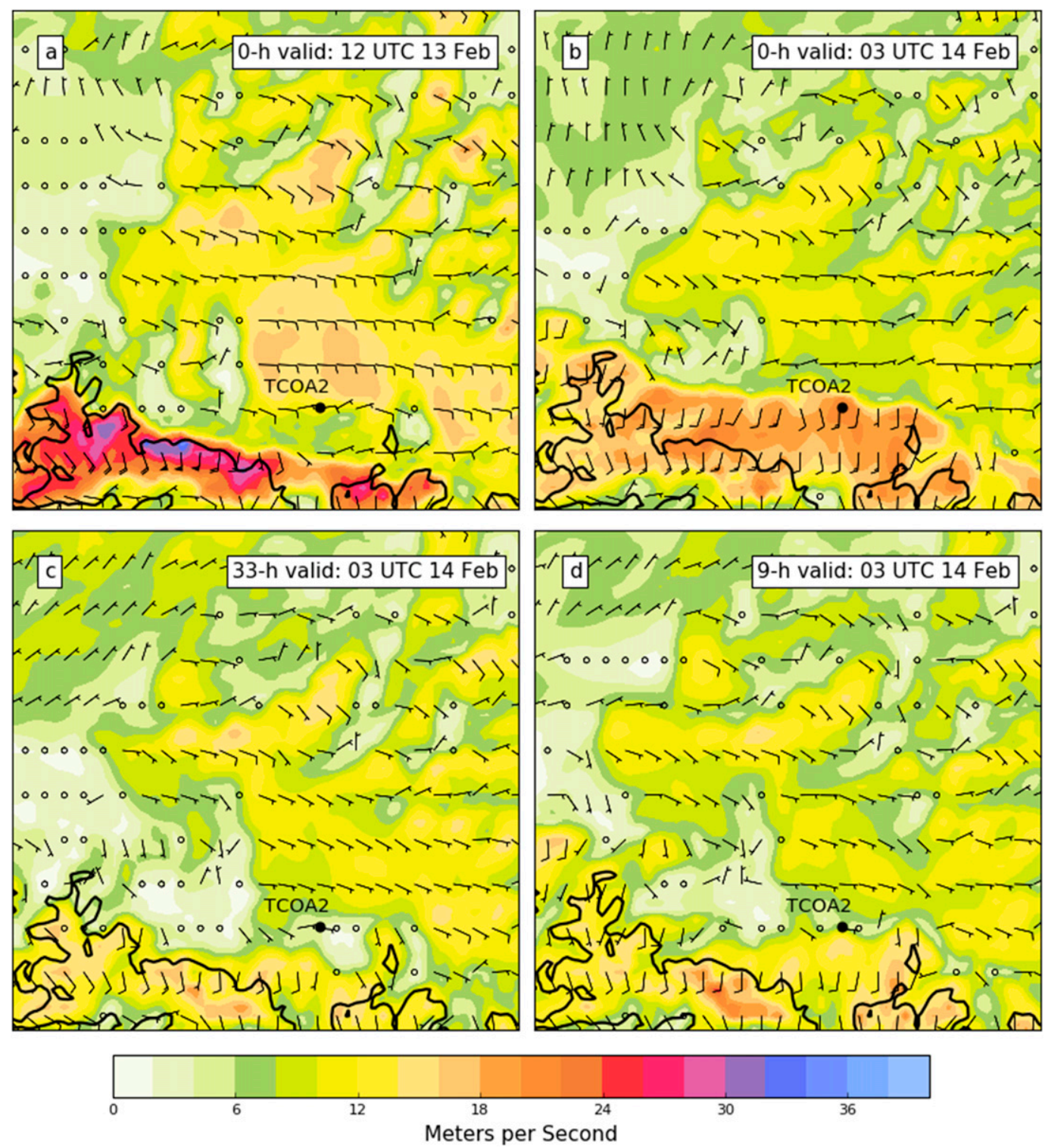

FIG. 13. HRRR-AK $10-\mathrm{m}$ wind barbs $\left(\mathrm{m} \mathrm{s}^{-1}\right)$ and wind gust contours $\left(\mathrm{m} \mathrm{s}^{-1}\right.$; shaded according the scale below) valid at 1200 UTC $13 \mathrm{Feb}$ for the (a) 0-h forecast, and at 0300 UTC 14 Feb for the (b) 0-, (c) 33-, and (d) 9-h forecasts. Half, full, and flag wind barbs represent 5,10 , and $25 \mathrm{~m} \mathrm{~s}^{-1}$, respectively. The solid black line represents the $1500-\mathrm{m}$ terrain contour in all plots.

14 February (Fig. 12c). Pressures began rising by 0000 UTC 15 February (Fig. 12d) as the embedded shortwave trough continued its counterclockwise spin within the cutoff low, with the HRRR-AK forecasting rises more rapidly than observed to the south of the Alaska Range.

In the Fairbanks-Tanana valley area (Fig. 6b), the mesoscale structure evident in the HRRR-AK forecasts of 2-m air temperature and 10-m wind between 1200 UTC 13 February and 0000 UTC 15 February are examined in Figs. 13-15. Figures 13a and 14a display 0-h forecasts of wind gusts and 2-m air temperature, respectively, before the onset of the first downslope windstorm. Strong wind gusts were confined to the higher elevations (Fig. 13a), contrasting with calm winds and colder temperatures at the valley floor (Fig. 14a). In Fairbanks, temperatures fell below $-20^{\circ} \mathrm{C}$. At 0300 UTC 14 February, the HRRR-AK 0 -h forecast highlights the development of localized downslope winds and higher temperatures in the lee of the Alaska Range, including the Fort Greely area (Figs. 13b and 14b). Easterly winds in the Tanana valley and higher temperatures over the elevated terrain to the north of the Tanana valley are evident as well. Wind speed and gust 

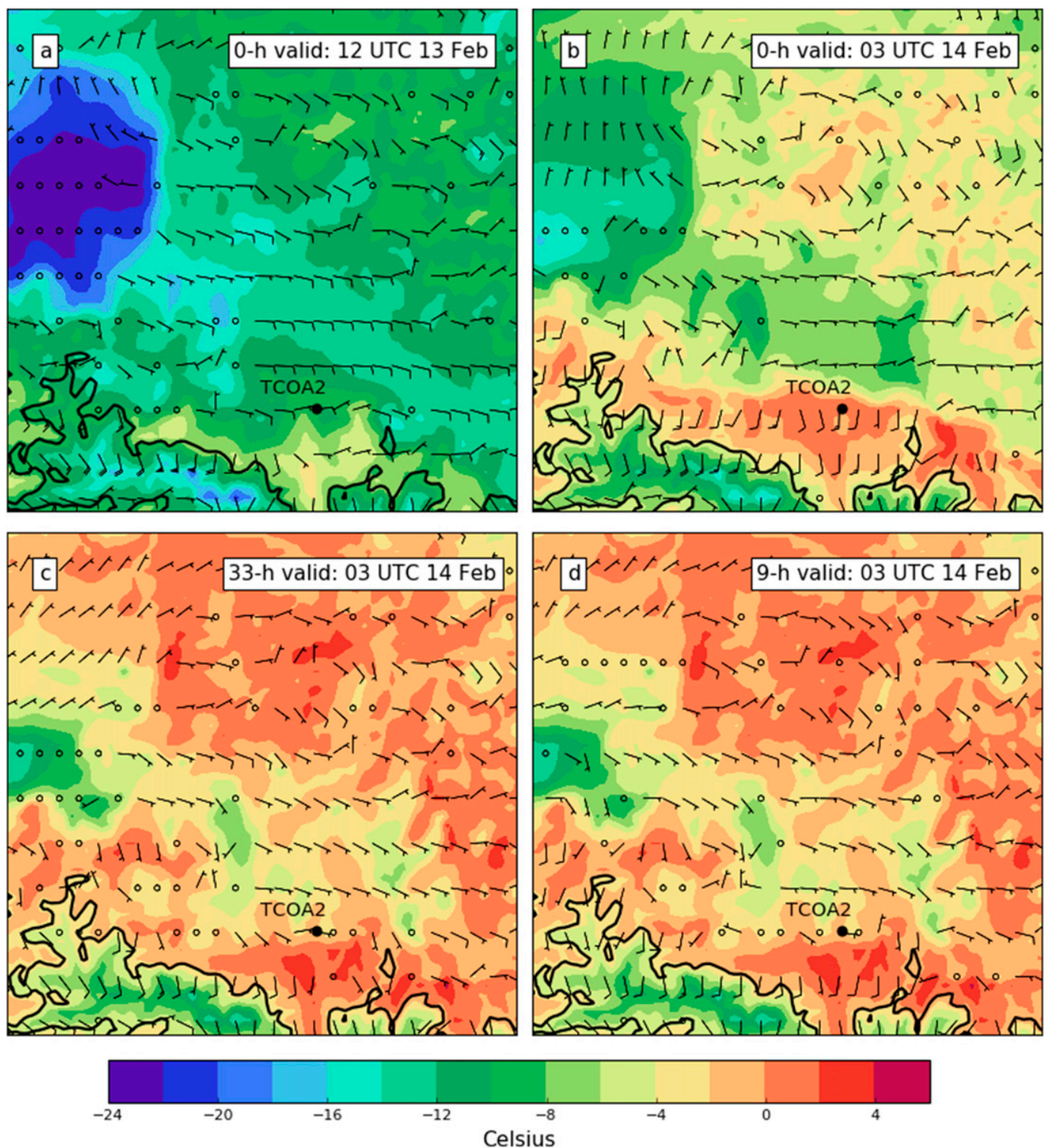

FIG. 14. HRRR-AK $10-\mathrm{m}$ wind barbs $\left(\mathrm{m} \mathrm{s}^{-1}\right)$ and 2-m temperature contours $\left({ }^{\circ} \mathrm{C}\right.$; shaded according the scale below) valid at 1200 UTC 13 Feb for the (a) 0-h forecast, and at 0300 UTC 14 Feb for the (b) 0-, (c) 33-, and (d) 9-h forecasts. Half, full, and flag wind barbs represent 5,10, and $25 \mathrm{~m} \mathrm{~s}^{-1}$, respectively. The solid black line represents the $1500-\mathrm{m}$ terrain contour in all plots.

forecasts valid at 0300 UTC 14 February, at lead times of $33 \mathrm{~h}$ (Fig. 13c) and $9 \mathrm{~h}$ (Fig. 13d), hint at enhanced winds in the lee of the Alaska Range, but the magnitudes of sustained winds and gusts are much too low. Additionally, the 33- and 9-h 2-m temperature forecasts valid at 0300 UTC 14 February produced widespread warming (Figs. 14c and $14 \mathrm{~d}$, respectively), which was neither observed nor seen in the 0-h HRRR-AK forecast (Fig. 14b).

Between the two downslope wind events (1200 UTC 14 February), low-lying areas within the upper Tanana valley warmed slightly compared to the day before, but calm winds and temperatures below $-20^{\circ} \mathrm{C}$ persisted near Fairbanks (Fig. 15a). At 2100 UTC 14 February, the second and more widespread period of downslope winds began. The HRRR-AK better predicted the strength and spatial extent of the second downslope wind event than the first event, as shown by $0-, 6-$, and $30-\mathrm{h}$ forecasts of 10-m wind barbs and 2-m temperature valid at 0000 UTC 15 February (Figs. 15b-d, respectively). However, the 30-h forecast indicated very high wind speeds over the higher terrain of the Alaska Range (Fig. 15c), leading to more widespread warming than analyzed as downward 

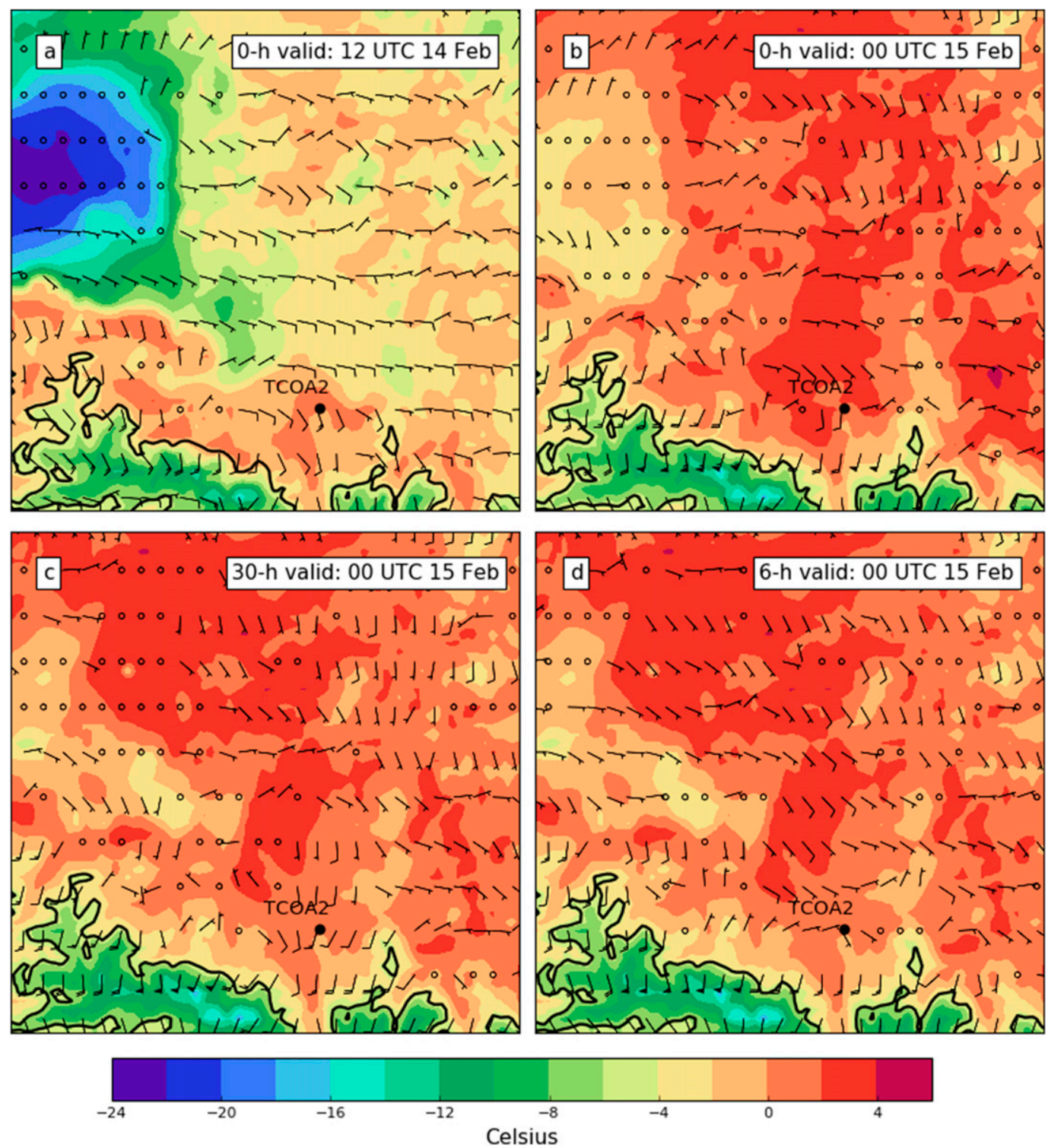

FIG. 15. HRRR-AK $10-\mathrm{m}$ wind barbs $\left(\mathrm{m} \mathrm{s}^{-1}\right)$ and 2 -m temperature contours $\left({ }^{\circ} \mathrm{C}\right.$; shaded according to the scale below) valid at 1200 UTC 14 Feb for the (a) 0-h forecast, and at 0000 UTC 15 Feb for the (b) 0-, (c) 30-, and (d) 6-h forecasts. Half, full, and flag wind barbs represent 5,10 , and $25 \mathrm{~m} \mathrm{~s}^{-1}$, respectively. The solid black line represents the $1500-\mathrm{m}$ terrain contour in all plots.

mixing combined with large-scale warm-air advection aloft (Fig. 15b).

\section{Summary and future work}

Experimental HRRR-AK forecasts from December 2016 to June 2017 were evaluated using altimeter setting data from the TA and NWS networks across Alaska. Since the model is scheduled for operational implementation in mid-2018, this research provides useful and timely guidance on some characteristics of HRRR-AK performance. In addition, this is the first study to illustrate applications of the Alaskan TA network data, the largest recent expansion of surface observations reporting continuously in Alaska.

Pressure differences arising from discrepancies between the model and actual terrain were removed by converting surface pressure observations and forecasts to the altimeter setting. The model's 0 -h forecasts of altimeter settings near NWS sites tend to be close to the observations at those locations as a result of the model's data assimilation procedures. However, larger discrepancies at the initial forecast hour are evident near the TA sites since those observations are not assimilated. The RMSE values from 


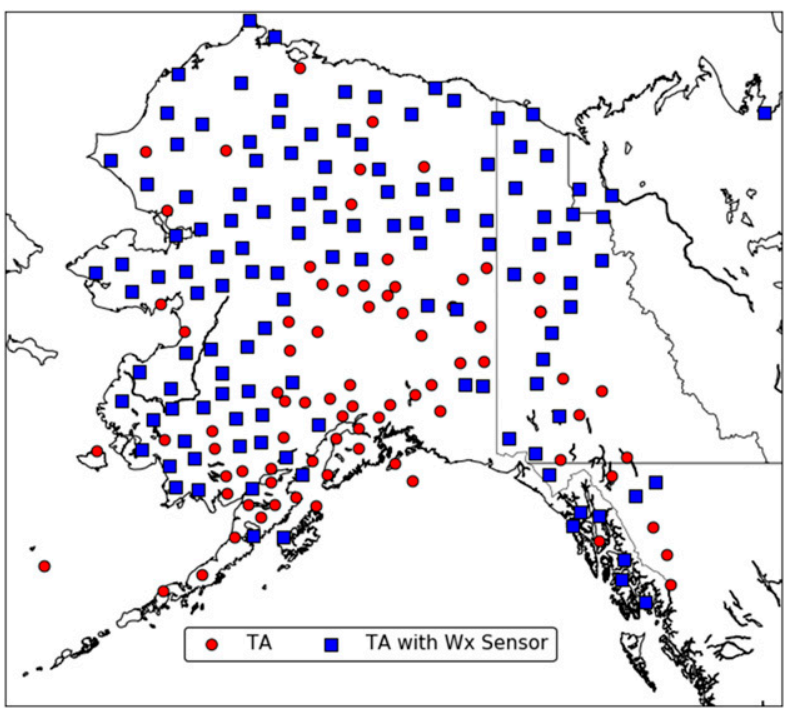

FIG. 16. TA station locations in Alaska and Canadian provinces in early 2018 with weather sensor systems (blue squares) or pressure sensors only (red dots).

the HRRR-AK 36-h altimeter setting forecasts are comparable at both NWS and TA locations, highlighting that the independent TA pressure observations, often in remote locations, are valuable additions for model verification. The HRRR-AK generally exhibited smallermagnitude spatial and temporal forecast errors relative to both the TA and NWS stations when compared to the errors from the GFS forecasts for the same station locations. Higher forecast errors occurred during an isolated period (18-22 January 2017), resulting from a code transition that limited the assimilation of surface observations.

A case study examined rapid warming and strong downslope winds in the upper reaches of the Tanana valley near Fort Greely during 12-15 February 2017. The dense network of stations in the Fort Greely area allowed for examination of the temporal evolution of these downslope winds on the HRRR-AK model's 3-km grid. It was expected in advance, then confirmed, that the HRRR-AK would not be able to capture many of the localized details of the two distinct downslope wind events. However, the HRRR-AK 0-h forecasts were very useful for diagnosing the spatial and temporal evolution of surface and upper-air conditions associated with the progression of a cutoff low in the Gulf of Alaska and the subsequent development of the two distinct periods of downslope winds. Overall, for lead times of $18-36 \mathrm{~h}$, the forecast accuracy for the synoptic-scale conditions in the Alaska region was generally adequate with regard to the timing and progression of upper-level pressure features. However, errors in the intensity and position of mesoscale features within the cutoff low may have led to excessive deepening of the surface low and downstream midtropospheric warm-air advection, resulting in more widespread warming and higher winds in the Fort Greely-Tanana valley area.

The benefits of the USArray for improved situational awareness, potential incorporation into data assimilation systems, and model validation will continue to be felt in the state of Alaska with the ongoing deployment of the network. The previous deployment strategy for the USArray transportable array was to limit seismic and atmospheric pressure observations to two years at each site in the continental United States. However, there is considerable interest among weather-sensitive Alaskan stakeholders in maintaining as many of the Alaskan TA stations as possible beyond 2019. Justification for that continued deployment has been enhanced by adding Vaisala all-in-one weather sensors measuring temperature, relative humidity, and wind to many of the TA stations (Fig. 16). Weather data from those sites are accessible for diverse applications via MesoWest. Since assimilating surface pressure observations is recognized to benefit model skill, work will begin soon to test assimilating the TA pressure observations into the initialization procedures for the HRRR-AK.

Acknowledgments. The authors thank the NOAA ESRL Global Systems Division for providing access to HRRR-AK forecasts and for generously using their time and modeling expertise to help make this study possible. This work was supported by the National Science Foundation (NSF Grants 1252315 and 1443046) and a NOAA Collaborative Science, Technology, and Applied Research (CSTAR) Program Award (NA13NWS4680003). TA pressure data access was provided by the IRIS Web Services and the Array Network Facility at Scripps Institution of Oceanography, University of California San Diego. The University of Utah Center for High Performance Computing (CHPC) provided computational hardware and software.

\section{REFERENCES}

Alaska Climate Research Center, 2017: Alaska Statewide Climate Summary: February 2017. Accessed 10 May 2017, http:// akclimate.org/Summary/Statewide/2017/Feb/.

Ancell, B. C., 2012: Examination of analysis and forecast errors of high-resolution assimilation, bias removal, and digital filter initialization with an ensemble Kalman filter. Mon. Wea. Rev., 140, 3992-4004, https://doi.org/10.1175/MWR-D-11-00319.1.

Benjamin, S. G., B. E. Schwartz, and R. E. Cole, 1999: Accuracy of ACARS wind and temperature observations determined by collocation. Wea. Forecasting, 14, 1032-1038, https://doi.org/ 10.1175/1520-0434(1999)014<1032:AOAWAT>2.0.CO;2. , and Coauthors, 2016: A North American hourly assimilation and model forecast cycle: The Rapid Refresh. Mon. Wea. Rev., 144, 1669-1694, https://doi.org/10.1175/MWR-D-15-0242.1. 
Bieniek, P. A., U. S. Bhatt, L. A. Rundquist, S. D. Lindsey, and X. D. Zhang, 2011: Large-scale climate controls of interior Alaska ice breakup. J. Climate, 24, 286-297, https://doi.org/ 10.1175/2010JCLI3809.1.

— objective methods. J. Appl. Meteor. Climatol., 51, 1276-1289, https://doi.org/10.1175/JAMC-D-11-0168.1.

— J J. E. Walsh, R. L. Thoman, and U. S. Bhatt, 2014: Using climate divisions to analyze variations and trends in Alaska temperature and precipitation. J. Climate, 27, 2800-2818, https://doi.org/10.1175/JCLI-D-13-00342.1.

_, U. S. Bhatt, J. E. Walsh, T. S. Rupp, J. Zhang, J. R. Krieger, and R. Lader, 2016: Dynamical downscaling of ERA-Interim temperature and precipitation for Alaska. J. Appl. Meteor. Climatol., 55, 635-654, https://doi.org/10.1175/JAMC-D-15-0153.1.

Blaylock, B. K., J. Horel, and S. Liston, 2017: Cloud archiving and data mining of High-Resolution Rapid Refresh model output. Comput. Geosci., 109, 43-50, https://doi.org/10.1016/j.cageo.2017.08.005.

Bluestein, H. B., 1992: Principles of Kinematics and Dynamics. Vol. I. Synoptic-Dynamic Meteorology in Midlatitudes. Oxford University Press, $431 \mathrm{pp}$.

Cassano, J. J., E. N. Cassano, M. W. Seefeldt, W. J. Gutowski Jr., and J. M. Glisan, 2016: Synoptic conditions during wintertime temperature extremes in Alaska. J. Geophys. Res. Atmos., 121, 3241-3262, https:doi.org/10.1002/2015JD024404.

Charles, M. E., and B. A. Colle, 2009: Verification of extratropical cyclones within the NCEP operational models. Part I: Analysis errors and short-term NAM and GFS forecasts. Wea. Forecasting, 24, 1173-1190, https://doi.org/10.1175/2009WAF2222169.1.

Colman, B. R., and C. F. Dierking, 1992: The taku wind of southeast Alaska: Its identification and prediction. Wea. Forecasting, 7, 49-64, https://doi.org/10.1175/1520-0434(1992) 007<0049:TTWOSA > 2.0.CO;2.

Colucci, S. J., and L. F. Bosart, 1979: Surface anticyclone behavior in NMC prediction models. Mon. Wea. Rev., 107, 377-394, https:// doi.org/10.1175/1520-0493(1979)107<0377:SABINP>2.0.CO;2.

Cullather, R. I., Y. K. Lim, L. N. Boisvert, L. Brucker, J. N. Lee, and S. M. J. Nowicki, 2016: Analysis of the warmest Arctic winter, 2015-2016. Geophys. Res. Lett., 43, 10 808-10816, https://doi.org/10.1002/2016GL071228.

Environmental Modeling Center, 2003: The GFS atmospheric model. NCEP Office Note 442, 14 pp., http://www.emc.ncep. noaa.gov/officenotes/newernotes/on442.pdf.

Grice, G. K., and A. L. Comisky, 1976: Thunderstorm climatology of Alaska. NOAA Tech. Memo. NWS AR-14, 36 pp., https:// repository.library.noaa.gov/view/noaa/13508/noaa_13508_DS1.pdf.

Hopkins, R. H., 1994: Anchorage windstorm of 1 December 1992. Wea. Forecasting, 9, 469-478, https://doi.org/10.1175/15200434(1994)009<0469:AWOD>2.0.CO;2.

Horel, J., and Coauthors, 2002: MesoWest: Cooperative mesonets in the western United States. Bull. Amer. Meteor. Soc., 83, 211-225, https://doi.org/10.1175/1520-0477(2002)083<0211: MCMITW $>2.3 . \mathrm{CO} ; 2$.

Hu, M., S. G. Benjamin, T. T. Ladwig, D. C. Dowell, S. S. Weygandt, C. R. Alexander, and J. S. Whitaker, 2017: GSI three-dimensional ensemble-variational hybrid data assimilation using a global ensemble for the regional Rapid Refresh model. Mon. Wea. Rev., 145, 4205-4225, https://doi.org/ 10.1175/MWR-D-16-0418.1.

Jacques, A. A., J. D. Horel, E. T. Crosman, and F. L. Vernon, 2015: Central and eastern U.S. surface pressure variations derived from the USArray network. Mon. Wea. Rev., 143, 1472-1493, https://doi.org/10.1175/MWR-D-14-00274.1.
,,,--- and,$- 2016 \mathrm{a}$ : EarthScope USArray Transportable Array (TA) surface pressure observations sampled at $1 \mathrm{~Hz}$ frequency. Research Data Archive, Computational and Information Systems Laboratory, National Center for Atmospheric Research, accessed 20 July 2017, https://doi.org/ 10.5065/D6028PRS.

$\_,-,-, \ldots$, and J. Tytell, 2016b: The Earthscope US Transportable Array $1 \mathrm{~Hz}$ surface pressure dataset. Geosci. Data J., 3, 29-36, https://doi.org/10.1002/gdj3.37.

$\longrightarrow, \ldots,-$, and $\_, 2017$ : Tracking mesoscale pressure perturbations using the USArray Transportable Array. Mon. Wea. Rev., 145, 3119-3142, https://doi.org/10.1175/MWR-D-16-0450.1.

Janjić, Z. I., 2003: A nonhydrostatic model based on a new approach. Meteor. Atmos. Phys., 82, 271-285, https://doi.org/ 10.1007/s00703-001-0587-6.

Kalnay, E., and Coauthors, 1996: The NCEP/NCAR 40-Year Reanalysis Project. Bull. Amer. Meteor. Soc., 77, 437-471, https:// doi.org/10.1175/1520-0477(1996)077<0437:TNYRP>2.0.CO;2.

Kleist, D. T., D. F. Parrish, J. C. Derber, R. Treadon, W. Wu, and S. Lord, 2009: Introduction of the GSI into the NCEP Global Data Assimilation System. Wea. Forecasting, 24, 1691-1705, https://doi.org/10.1175/2009WAF2222201.1.

Klemp, J. B., 2011: A terrain-following coordinate with smoothed coordinate surfaces. Mon. Wea. Rev., 139, 2163-2169, https:// doi.org/10.1175/MWR-D-10-05046.1.

Lawson, J., and J. Horel, 2015a: Analysis of the 1 December 2011 Wasatch downslope windstorm. Wea. Forecasting, 30, 115135, https://doi.org/10.1175/WAF-D-13-00120.1.

—_, and ——, 2015b: Ensemble forecast uncertainty of the 1 December 2011 Wasatch downslope windstorm. Wea. Forecasting, 30, 1749-1761, https://doi.org/10.1175/ WAF-D-15-0034.1.

Madaus, L. E., G. J. Hakim, and C. F. Mass, 2014: Utility of dense pressure observations for improving mesoscale analyses and forecasts. Mon. Wea. Rev., 142, 2398-2413, https://doi.org/ 10.1175/MWR-D-13-00269.1.

McCorkle, T. A., 2017: An evaluation of the experimental HighResolution Rapid Refresh-Alaska during winter 2017. Dept. of Atmospheric Sciences, University of Utah, $73 \mathrm{pp}$.

McMurdie, L. A., and J. H. Casola, 2009: Weather regimes and forecast errors in the Pacific Northwest. Wea. Forecasting, $\mathbf{2 4}$ 829-842, https://doi.org/10.1175/2008WAF2222172.1.

Mesquita, M. S., D. E. Atkinson, and K. I. Hodges, 2010: Characteristics and variability of storm tracks in the North Pacific, Bering Sea, and Alaska. J. Climate, 23, 294-311, https://doi.org/ 10.1175/2009JCLI3019.1.

Mohr, M., 2004: Problems with the mean sea level pressure field over the western United States. Mon. Wea. Rev., 132, 1952-1965, https:// doi.org/10.1175/1520-0493(2004)132<1952:PWTMSL>2.0.CO;2.

Murray, J. M., Jr., 1956: Strong surface winds at Big Delta, Alaska. Mon. Wea. Rev., 84, 15-24, https://doi.org/10.1175/1520-0493 (1956)084<0015:SSWABD > 2.0.CO;2.

Nance, L. B., and B. R. Colman, 2000: Evaluating the use of a nonlinear two-dimensional model in downslope windstorm forecasts. Wea. Forecasting, 15, 715-729, https://doi.org/ 10.1175/1520-0434(2000)015<0715:ETUOAN>2.0.CO;2.

National Weather Service, 2014: Global Forecast Systems (GFS) update: Effective December 17, 2014. NWS Tech. Implementation Notice 14-46, http://www.nws.noaa.gov/om/ notification/tin14-46gfs.htm.

NCEP, 2015: NCEP GFS 0.25 Degree Global Forecast Grids Historical Archive. Research Data Archive, Computational and Information Systems Laboratory, National Center for 
Atmospheric Research, accessed 29 Mar 2018, https://doi.org/ 10.5065/D65D8PWK.

Overland, J. E., and N. Bond, 1993: The influence of coastal orography: The Yakutat storm. Mon. Wea. Rev., 121, 1388-1397, https:// doi.org/10.1175/1520-0493(1993)121<1388:TIOCOT>2.0.CO;2.

Papineau, J. M., 2001: Wintertime temperature anomalies in Alaska correlated with ENSO and PDO. Int. J. Climatol., 21, 1577-1592, https://doi.org/10.1002/joc.686.

Partain, J. L., and Coauthors, 2016: An assessment of the role of anthropogenic climate change in the Alaska fire season of 2015. Bull. Amer. Meteor. Soc., 97, S14-S18, https://doi.org/ 10.1175/BAMS-D-16-0149.1.

Pauley, P. M., 1998: An example of uncertainty in sea level pressure reduction. Wea. Forecasting, 13, 833-850, https://doi.org/ 10.1175/1520-0434(1998)013<0833:AEOUIS > 2.0.CO;2.

Pavlis, G. L., K. Sigloch, S. Burdick, M. J. Fouch, and F. L. Vernon, 2012: Unraveling the geometry of the Farallon plate: Synthesis of three-dimensional imaging results from USArray. Tectonophysics, 532-535, 82-102, https://doi.org/10.1016/j.tecto.2012.02.008.

Reap, R. M., 1991: Climatological characteristics and objective prediction of thunderstorms over Alaska. Wea. Forecasting, 6, 309-319, https://doi.org/10.1175/1520-0434(1991)006<0309: $\mathrm{CCAOPO}>2.0 . \mathrm{CO} ; 2$

Rodionov, S. N., J. E. Overland, and N. A. Bond, 2005: The Aleutian low and winter climatic conditions in the Bering Sea. Part I: Classification. J. Climate, 18, 160-177, https://doi.org/10.1175/JCLI3253.1.

Searby, H. W., 1968: Climate of the states: Alaska. U.S. Dept. of Commerce ESSA Weather Bureau Rep. 60-49, 23 pp.

Shulski, M., and G. Wendler, 2007: The Climate of Alaska. University of Alaska Press, 216 pp.

_ J. Walsh, E. Stevens, and R. Thoman, 2010: Diagnosis of extended cold-season temperature anomalies in Alaska. Mon. Wea. Rev., 138, 453-462, https://doi.org/10.1175/2009MWR3039.1.

Skamarock, W. C., and Coauthors, 2008: A description of the Advanced Research WRF version 3. NCAR Tech. Note NCAR/ TN-475+STR, 113 pp., https://dx.doi.org/10.5065/D68S4MVH.

Thompson, D. W. J., and J. M. Wallace, 1998: The Arctic Oscillation signature in the wintertime geopotential height and temperature fields. Geophys. Res. Lett., 25, 1297-1300, https:// doi.org/10.1029/98GL00950.

Tytell, J., F. Vernon, M. Hedlin, C. de Groot Hedlin, J. Reyes, B. Busby, K. Hafner, and J. Eakins, 2016: The USArray Transportable Array as a platform for weather observation and research. Bull. Amer. Meteor. Soc., 97, 603-619, https:// doi.org/10.1175/BAMS-D-14-00204.1.

Walsh, J. E., P. A. Bieniek, B. Brettschneider, E. S. Euskirchen, R. Lader, and R. L. Thoman, 2017: The exceptionally warm winter of 2015/16 in Alaska. J. Climate, 30, 2069-2088, https:// doi.org/10.1175/JCLI-D-16-0473.1.

Wang, X., D. Parrish, D. Kleist, and J. Whitaker, 2013: GSI 3DVarbased ensemble-variational hybrid data assimilation for NCEP Global Forecast System: Single-resolution experiments. Mon. Wea. Rev., 141, 4098-4117, https://doi.org/ 10.1175/MWR-D-12-00141.1.

Wheatley, D. M., and D. J. Stensrud, 2010: The impact of assimilating surface pressure observations on severe weather events in a WRF mesoscale ensemble system. Mon. Wea. Rev., 138, 1673-1694, https://doi.org/10.1175/ 2009MWR3042.1.

Whitaker, J. S., T. M. Hamill, X. Wei, Y. Song, and Z. Toth, 2008: Ensemble data assimilation with the NCEP Global Forecast System. Mon. Wea. Rev., 136, 463-482, https://doi.org/10.1175/ 2007MWR2018.1.

Wilson, J. G., and J. E. Overland, 1986: Meteorology. The Gulf of Alaska, Physical Environment and Biological Resources, D. W. Hood and S. T. Zimmerman, Eds., Alaska Office, Ocean Assessments Division, National Oceanic and Atmospheric Administration, 31-56.

Wu, W. S., R. J. Purser, and D. F. Parrish, 2002: Three-dimensional variational analysis with spatially inhomogeneous covariances. Mon. Wea. Rev., 130, 2905-2916, https://doi.org/10.1175/15200493(2002)130<2905:TDVAWS > 2.0.CO;2.

Yang, Y., and M. H. Ritzwoller, 2008: Teleseismic surface wave tomography in the western US using the Transportable Array component of USArray. Geophys. Res. Lett., 35, L04308, https://doi.org/10.1029/2007GL032278. 